\title{
Solution syntheses of protected Type-II Lewis blood group oligosaccharides: a study for automated synthesis
}

\author{
Kerry Routenberg Love and Peter H. Seeberger
}

\section{Supplementary Information}

\section{Table of Contents}

General Methods.

NMR Spectra for Precursor Compounds to Compound 23.........................S4-S7

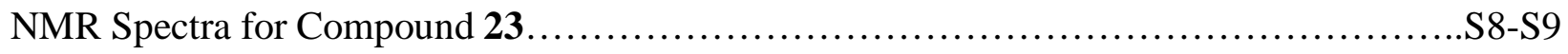

NMR Spectra for Precursor Compounds to Compound 7.........................S10-S11

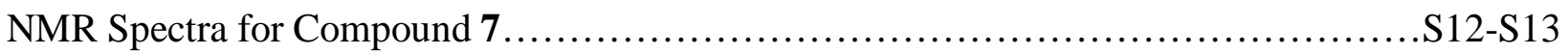

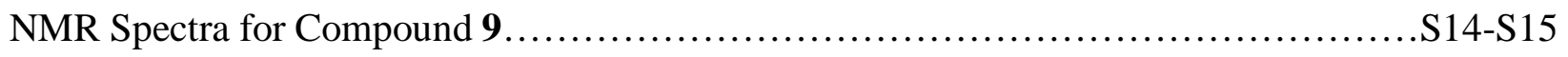

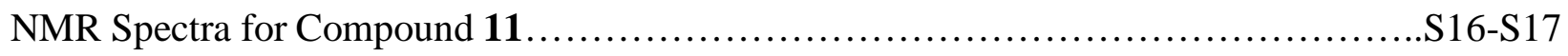

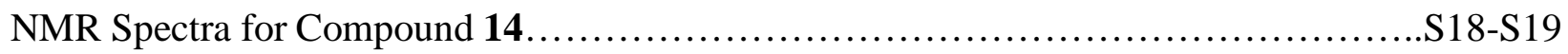

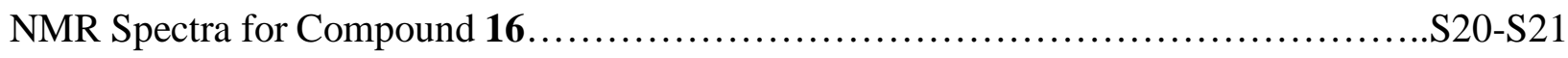

NMR Spectra for Compound 19............................................ 223

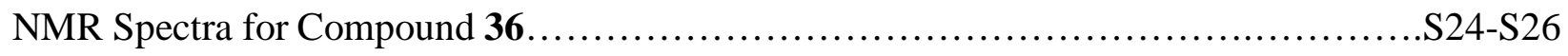

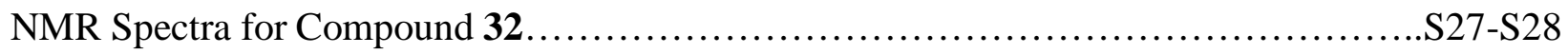

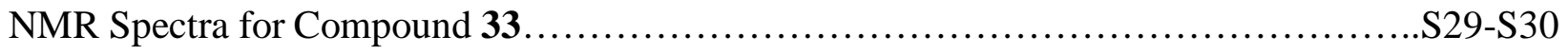

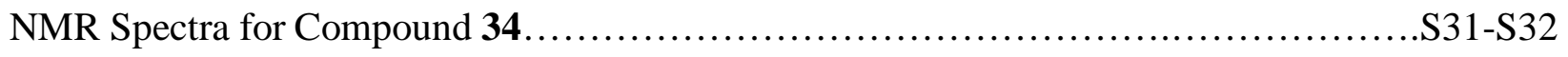


NMR Spectra for Compound 35. S33-S34

NMR Spectra for Compound 37 . S35-S36

NMR Spectra for Compound 39.

$. \mathrm{S} 37-\mathrm{S} 38$ 
General Methods. All chemicals were reagent grade and used as supplied unless otherwise noted. Dichloromethane $\left(\mathrm{CH}_{2} \mathrm{Cl}_{2}\right)$, tetrahydrofuran (THF), and toluene were purified by a JT Baker Cycle-Tainer Solvent Delivery System. Analytical thin-layer chromatography was performed on E. Merck silica gel $60 \mathrm{~F}_{254}$ plates $(0.25 \mathrm{~mm})$. Compounds were visualized by dipping the plates in a cerium sulfate-ammonium molybdate solution followed by heating. Liquid flash column chromatography was performed using forced flow of the indicated solvent on Silicycle silica (230 - 400 mesh). ${ }^{1} \mathrm{H}$ NMR spectra were obtained using a $400 \mathrm{MHz}$ or 500 $\mathrm{MHz}$ spectrometer and are reported in parts per million $(\delta)$ relative to $\mathrm{CDCl}_{3}(7.27 \mathrm{ppm})$. Coupling constants $(J)$ are reported in Hertz $(\mathrm{Hz}) .{ }^{13} \mathrm{C}$ NMR spectra were obtained at either 100 $\mathrm{MHz}$ or $125 \mathrm{MHz}$ and are reported in $\delta$ relative to $\mathrm{CDCl}_{3}(77.23 \mathrm{ppm})$ as an internal reference.

${ }^{31} \mathrm{P}$ spectra were obtained at $120 \mathrm{MHz}$ and are reported in $\delta$ relative to $\mathrm{H}_{3} \mathrm{PO}_{4}(0.0 \mathrm{ppm})$ as an external reference. Optical rotations were measured at room temperature. 


\section{Precursor to Compound 23}
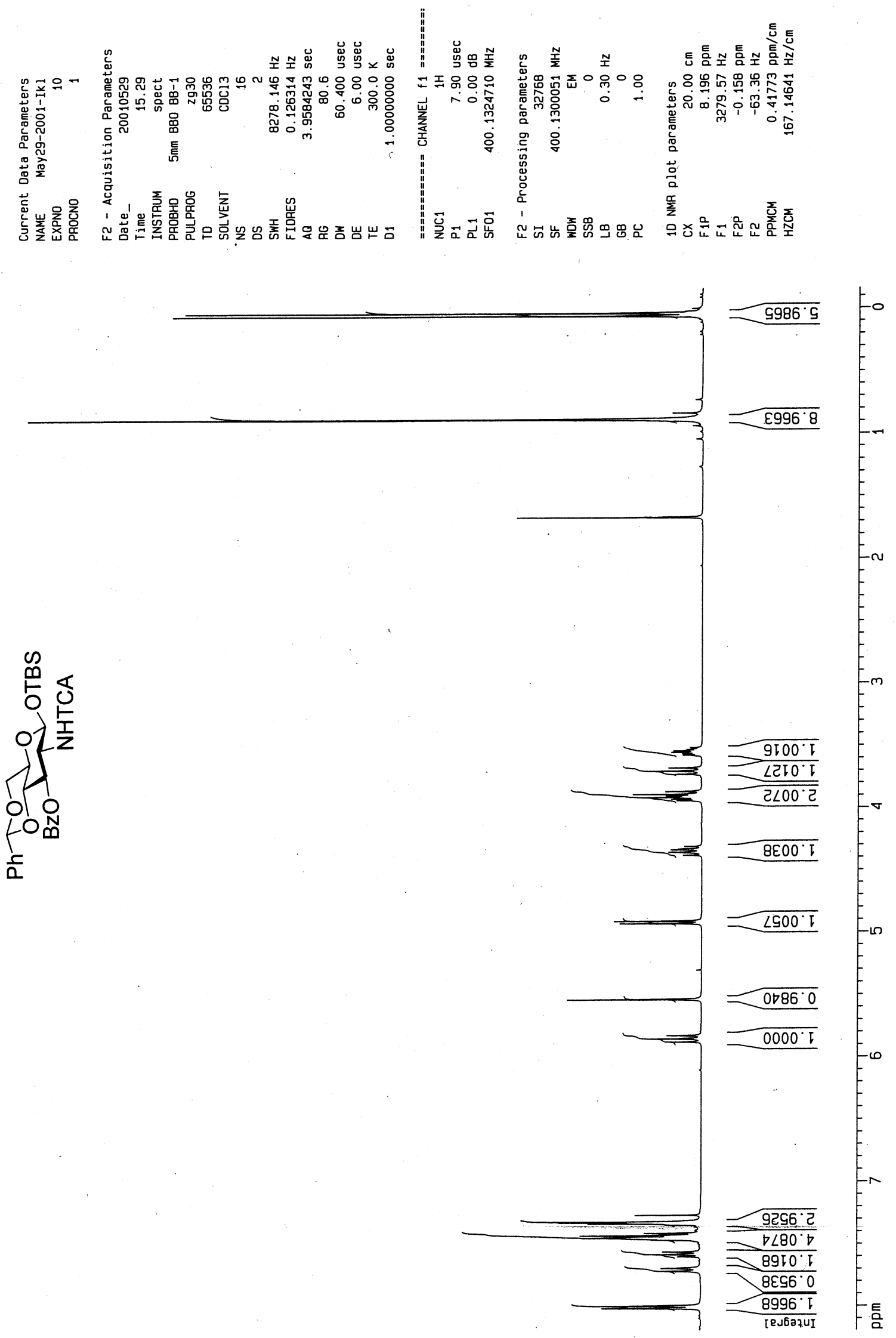


\section{Precursor to Compound 23}
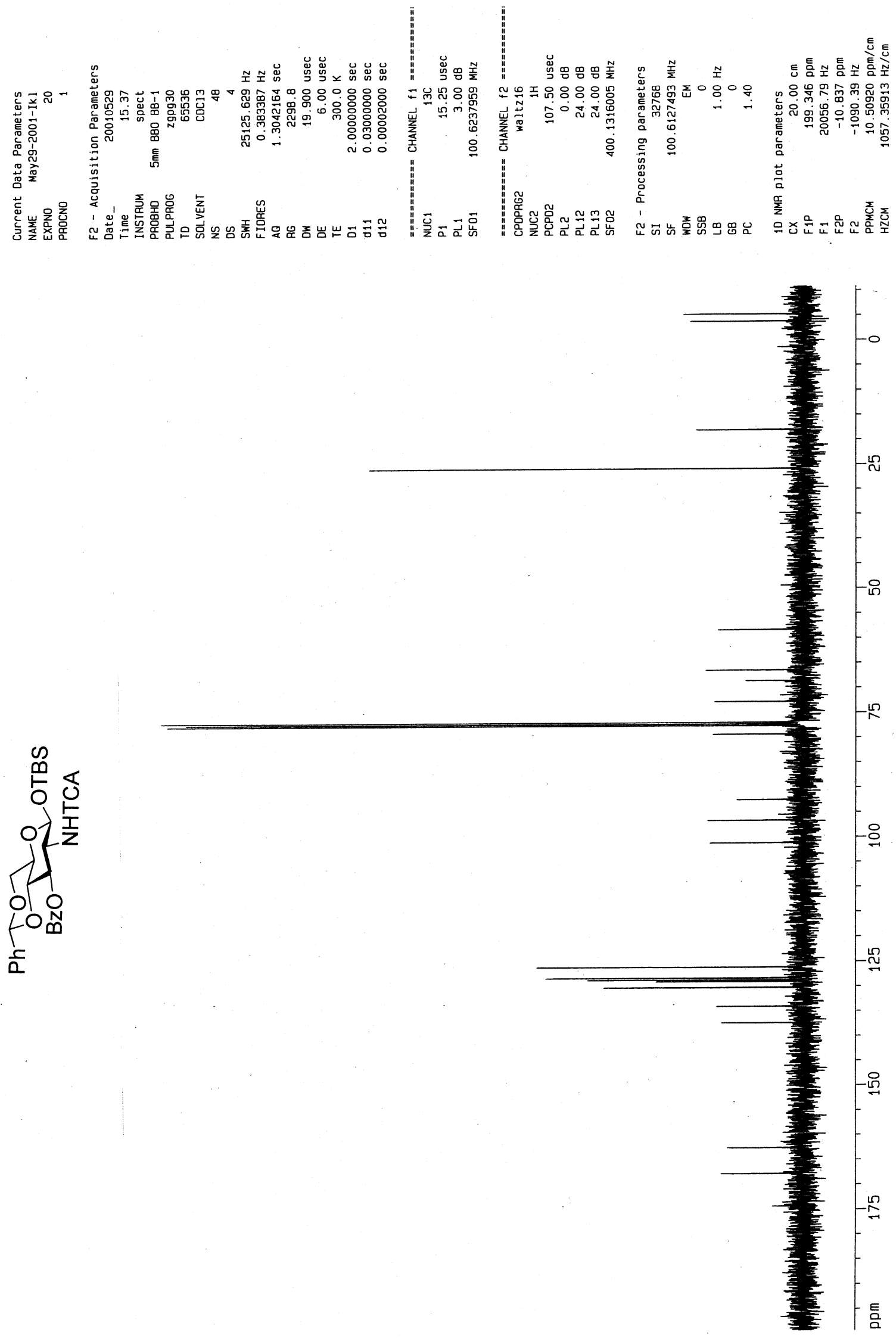


\section{Precursor to Compound 23}
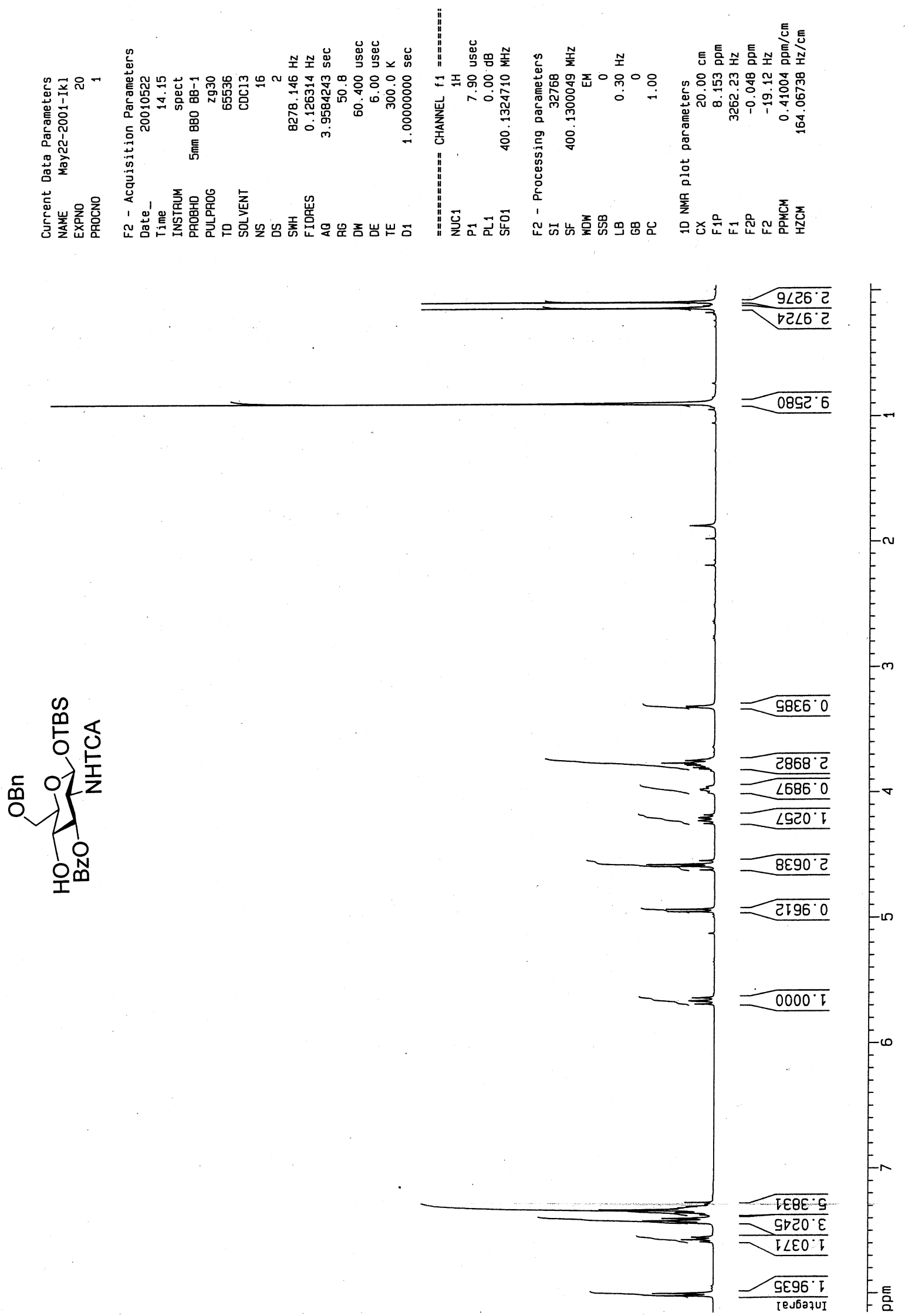


\section{Precursor to Compound 23}
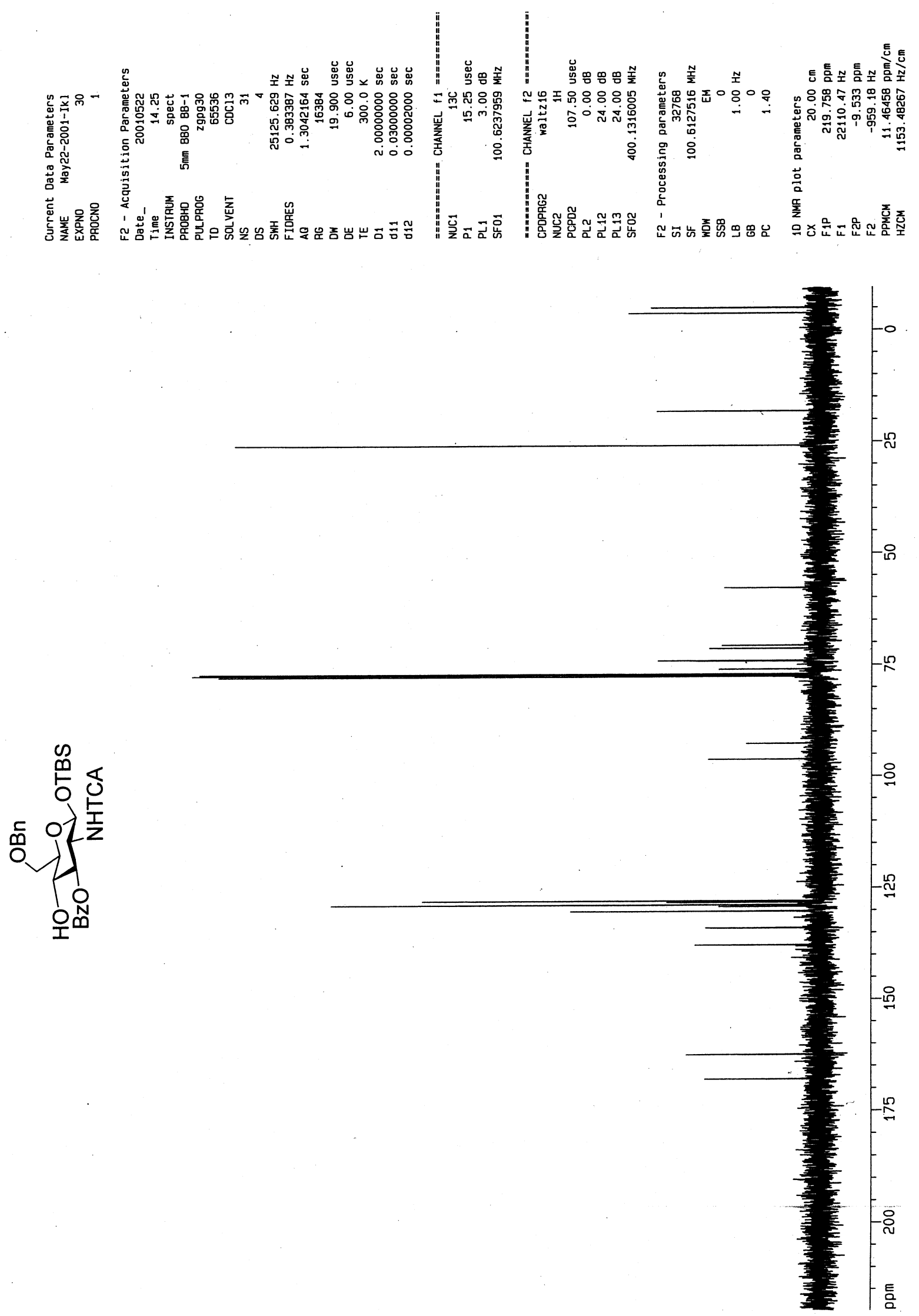
Compound 23
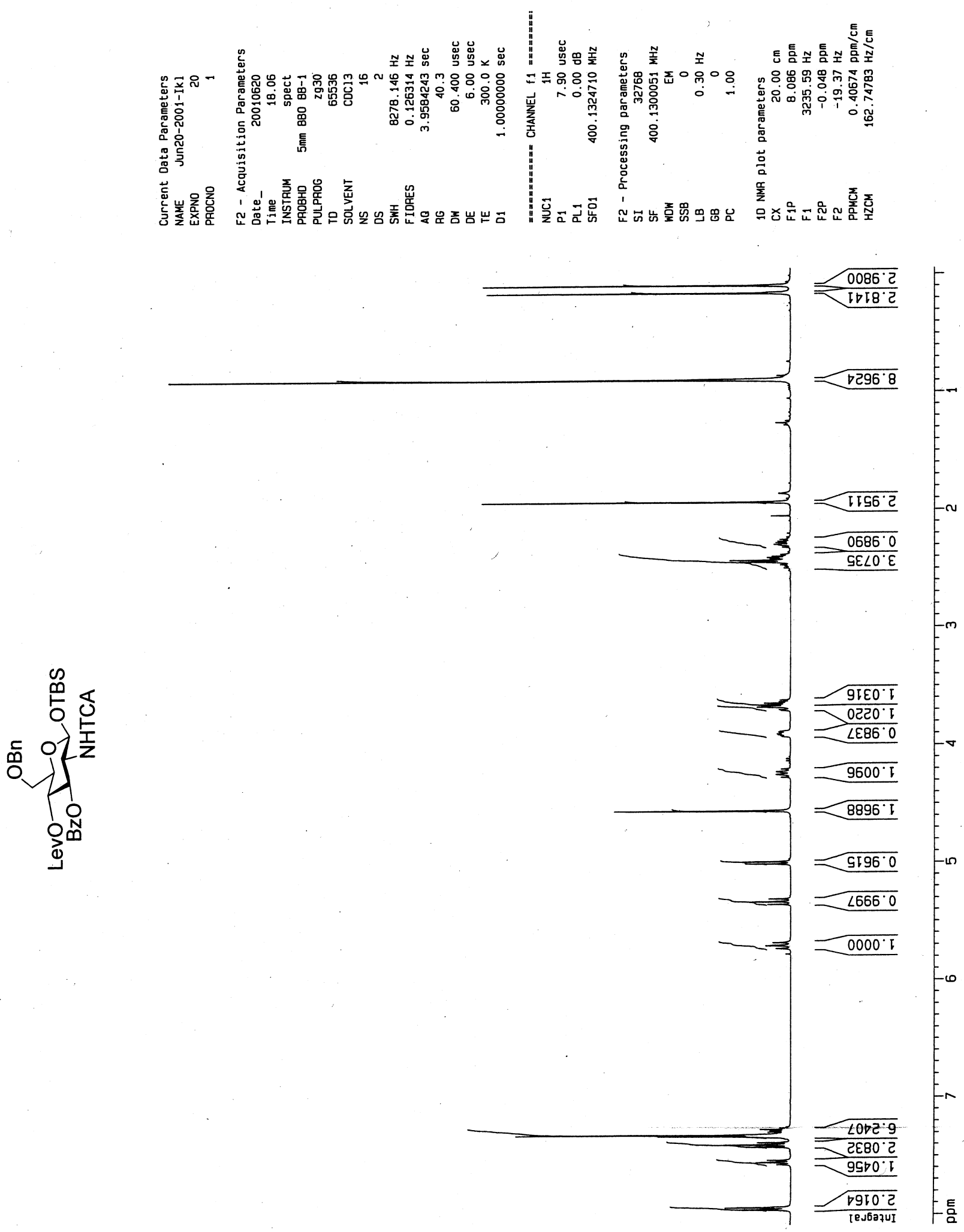
Compound 23
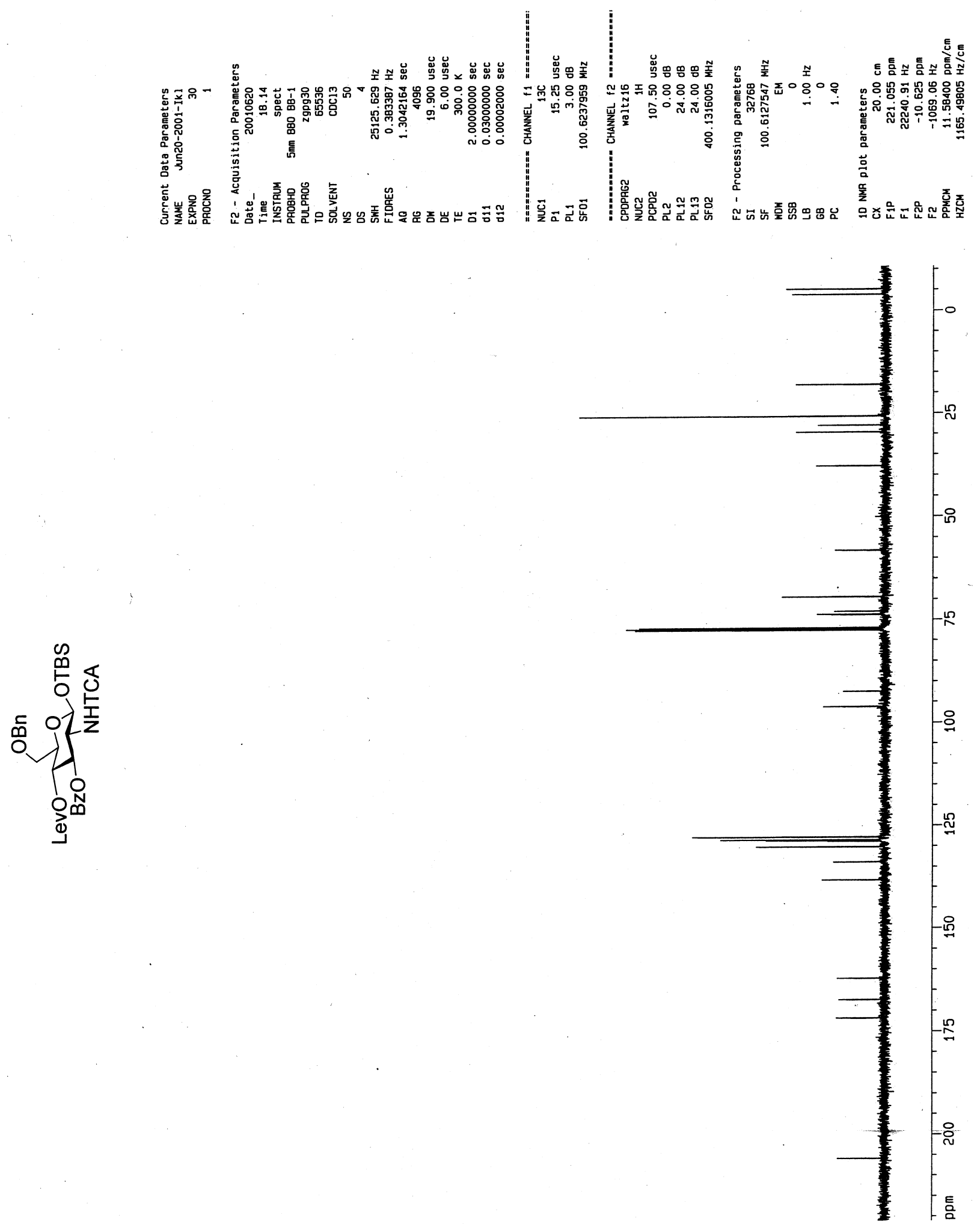


\section{Precursor to Compound 7}
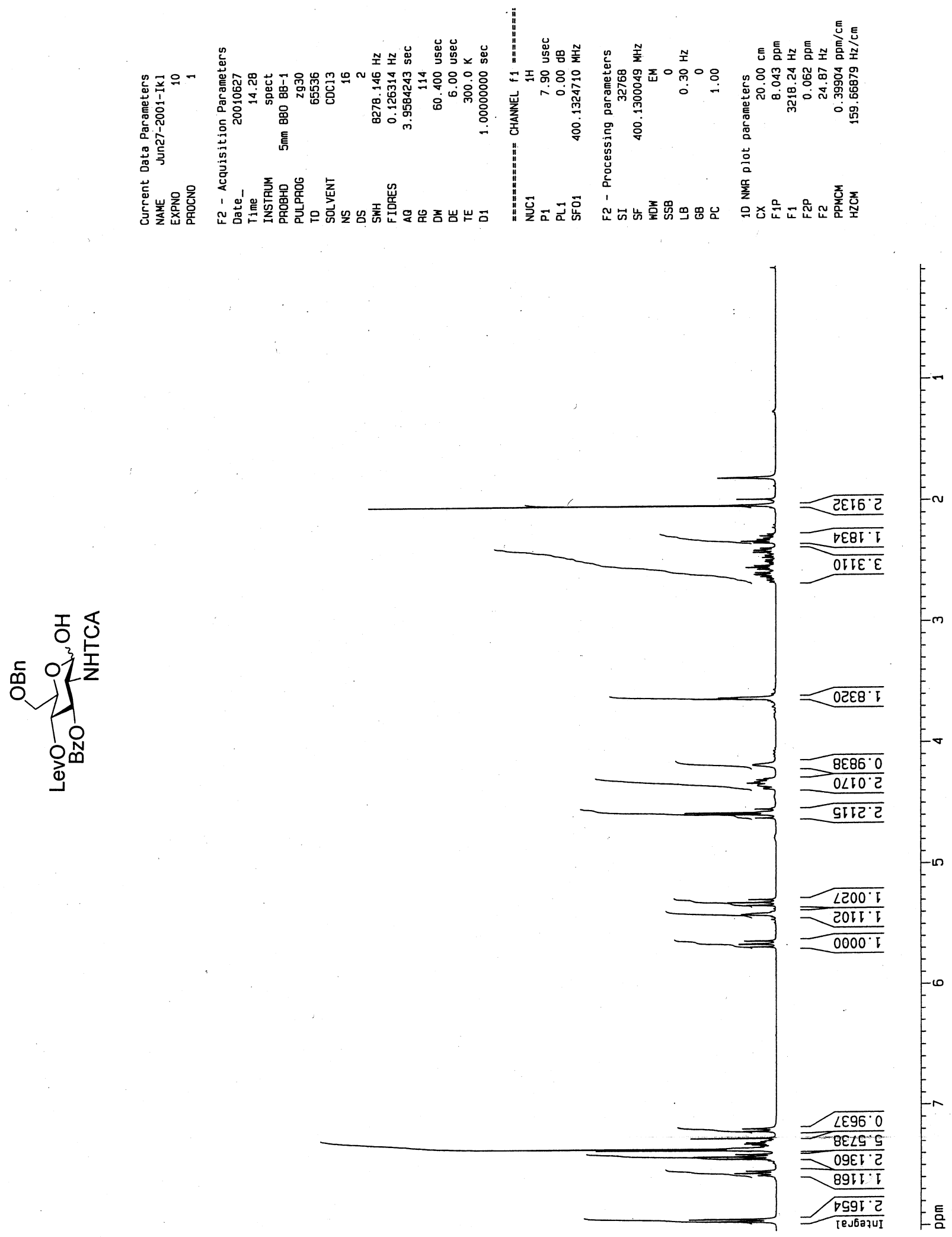


\section{Precursor to Compound 7}
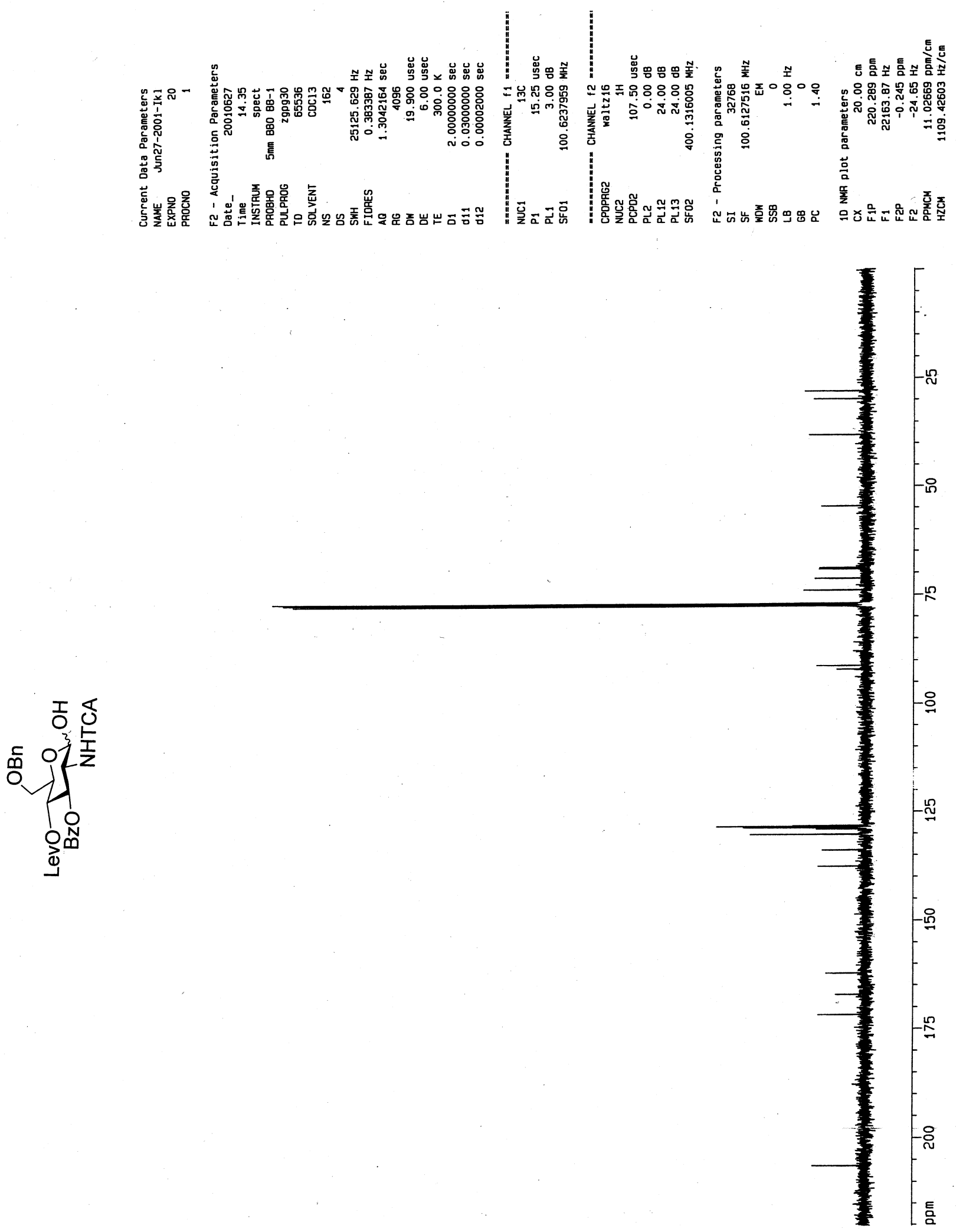


\section{Compound 7}
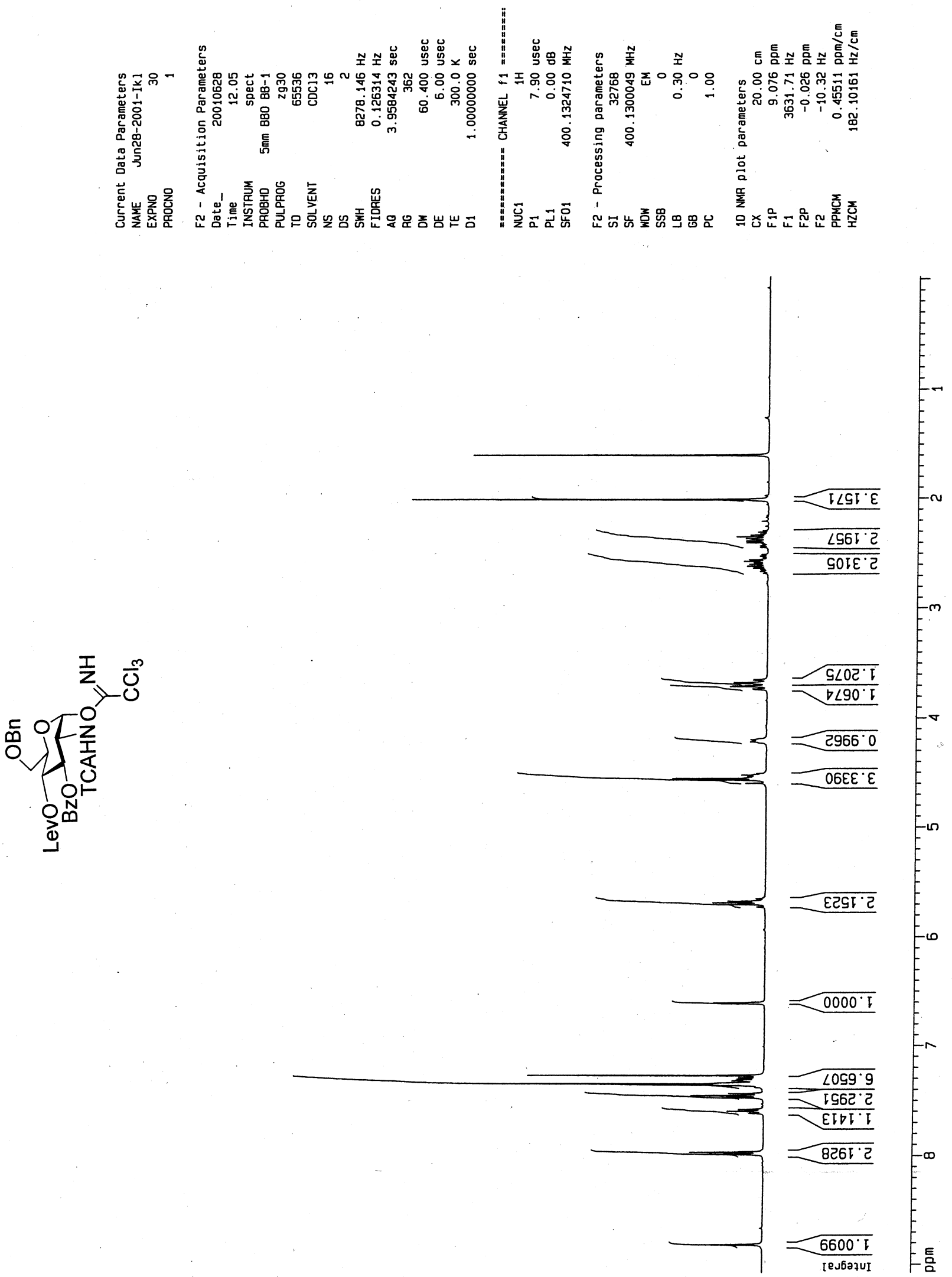
Compound 7
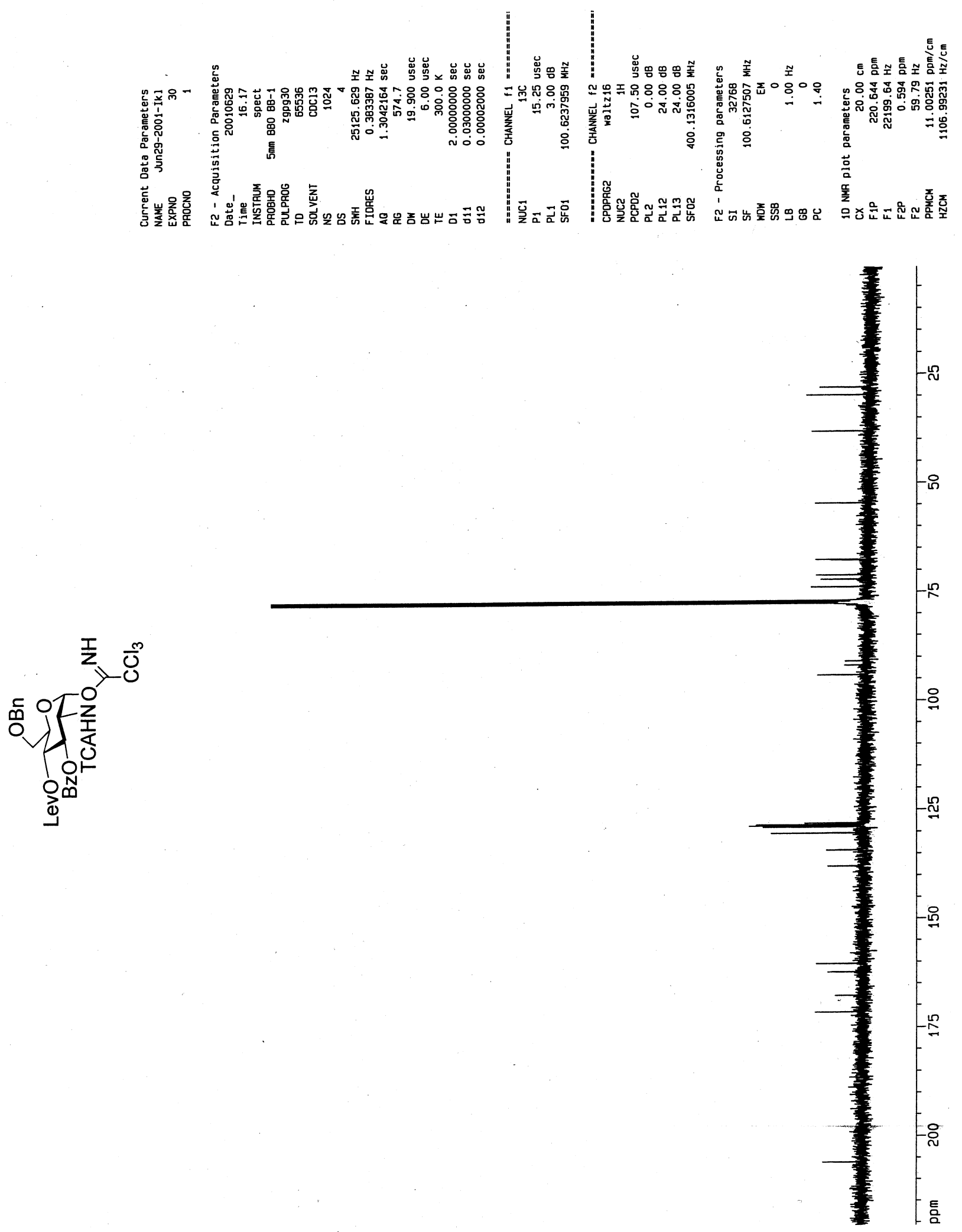
Compound 9

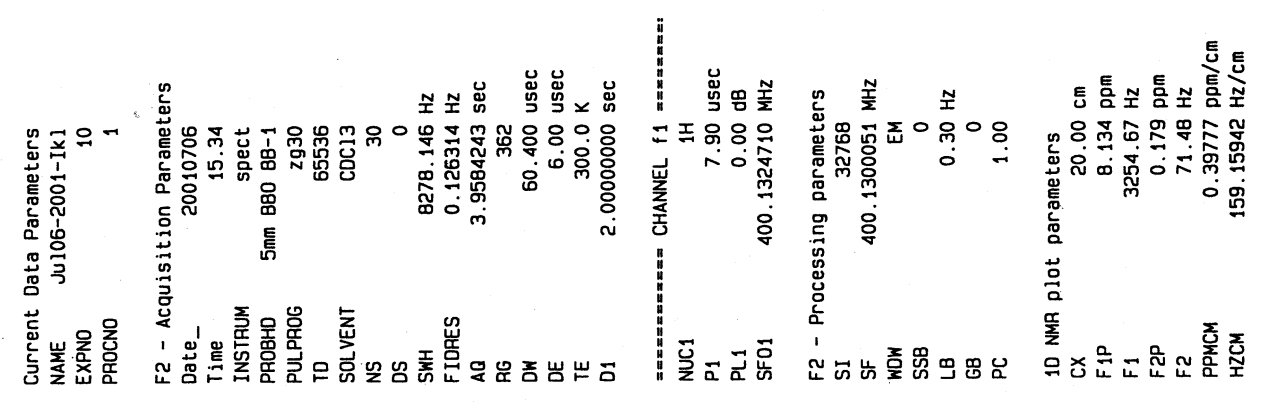

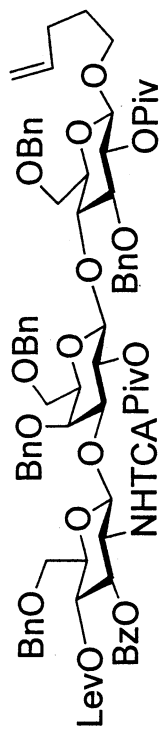

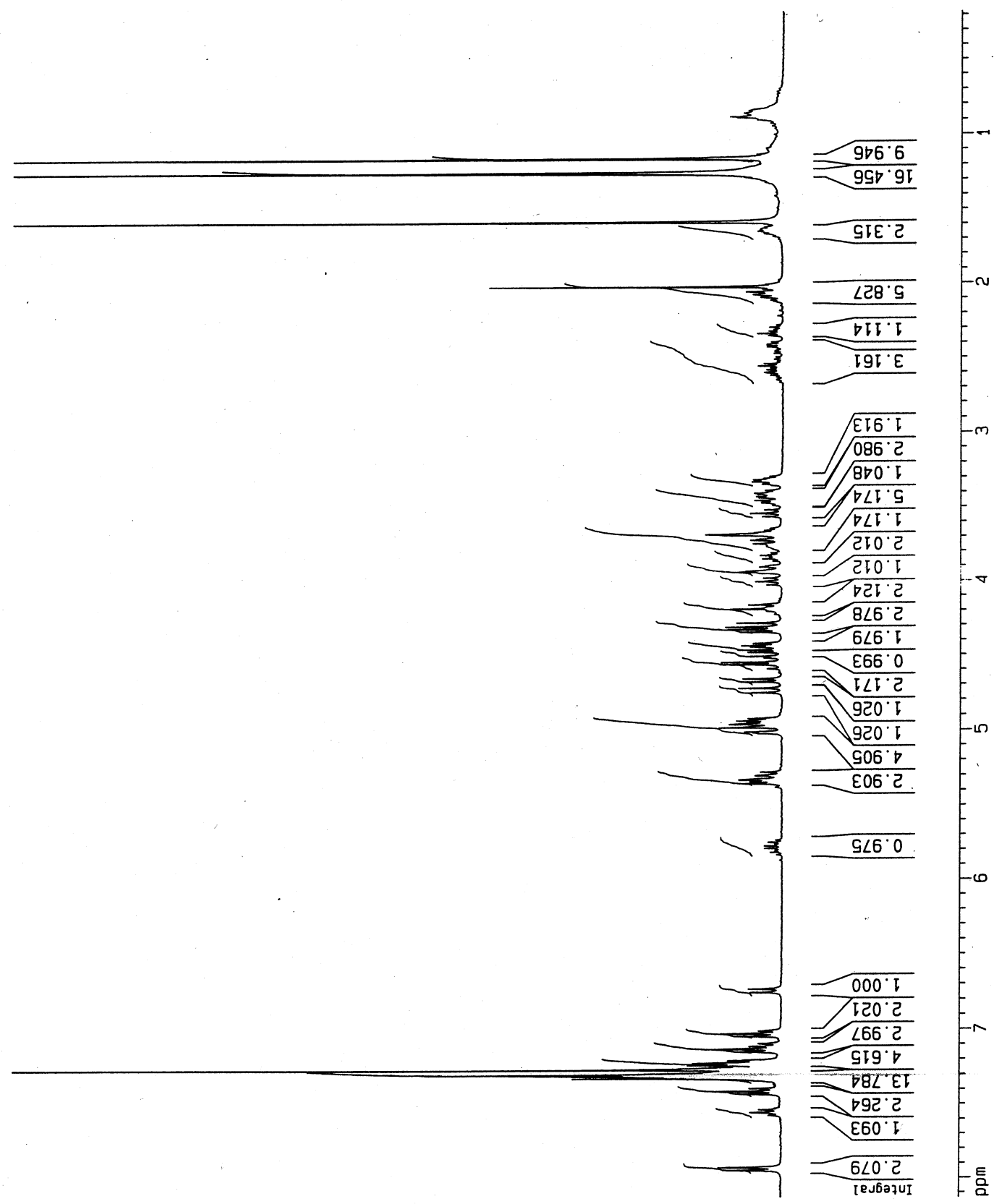




\section{Compound 9}
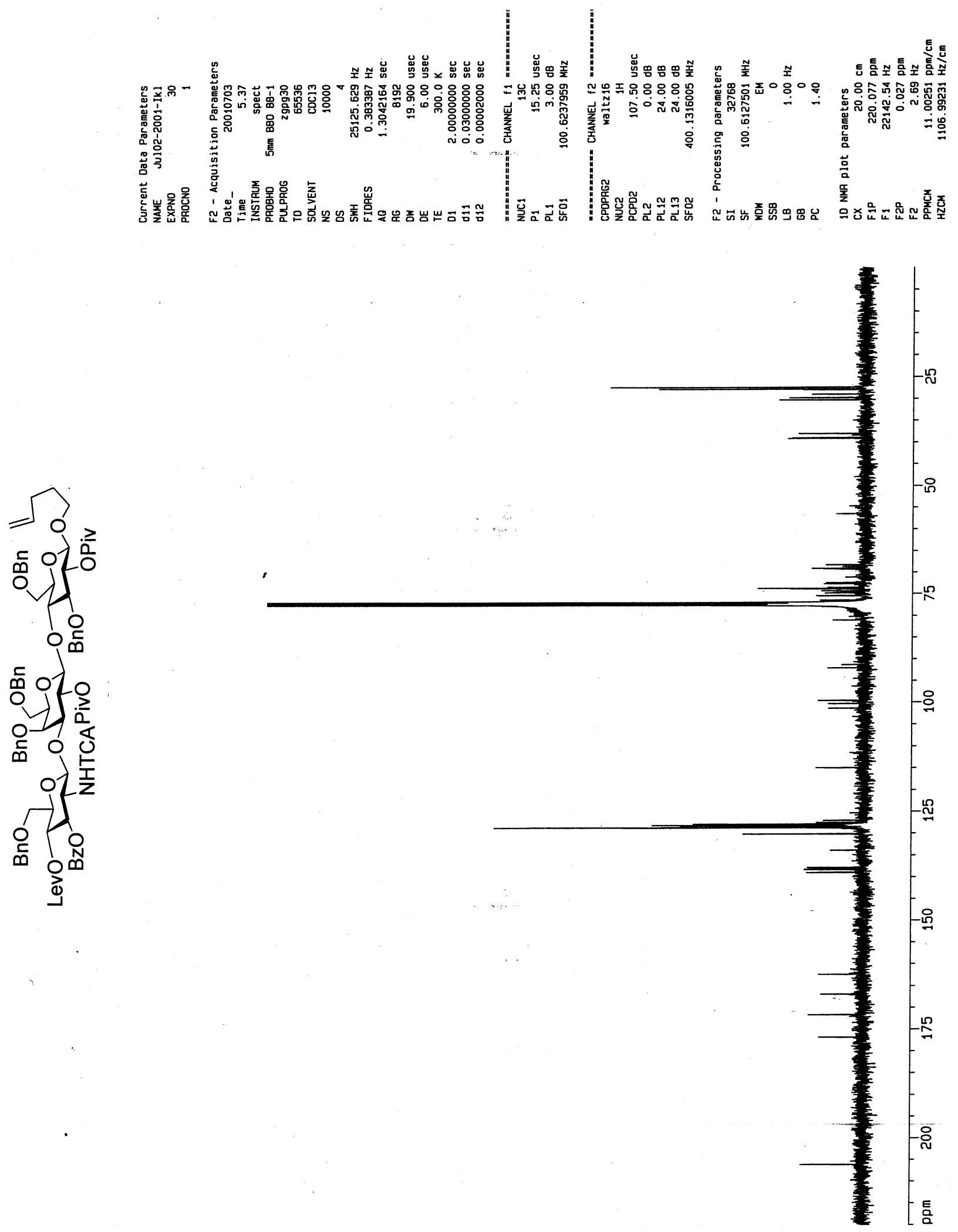


\section{Compound 11}
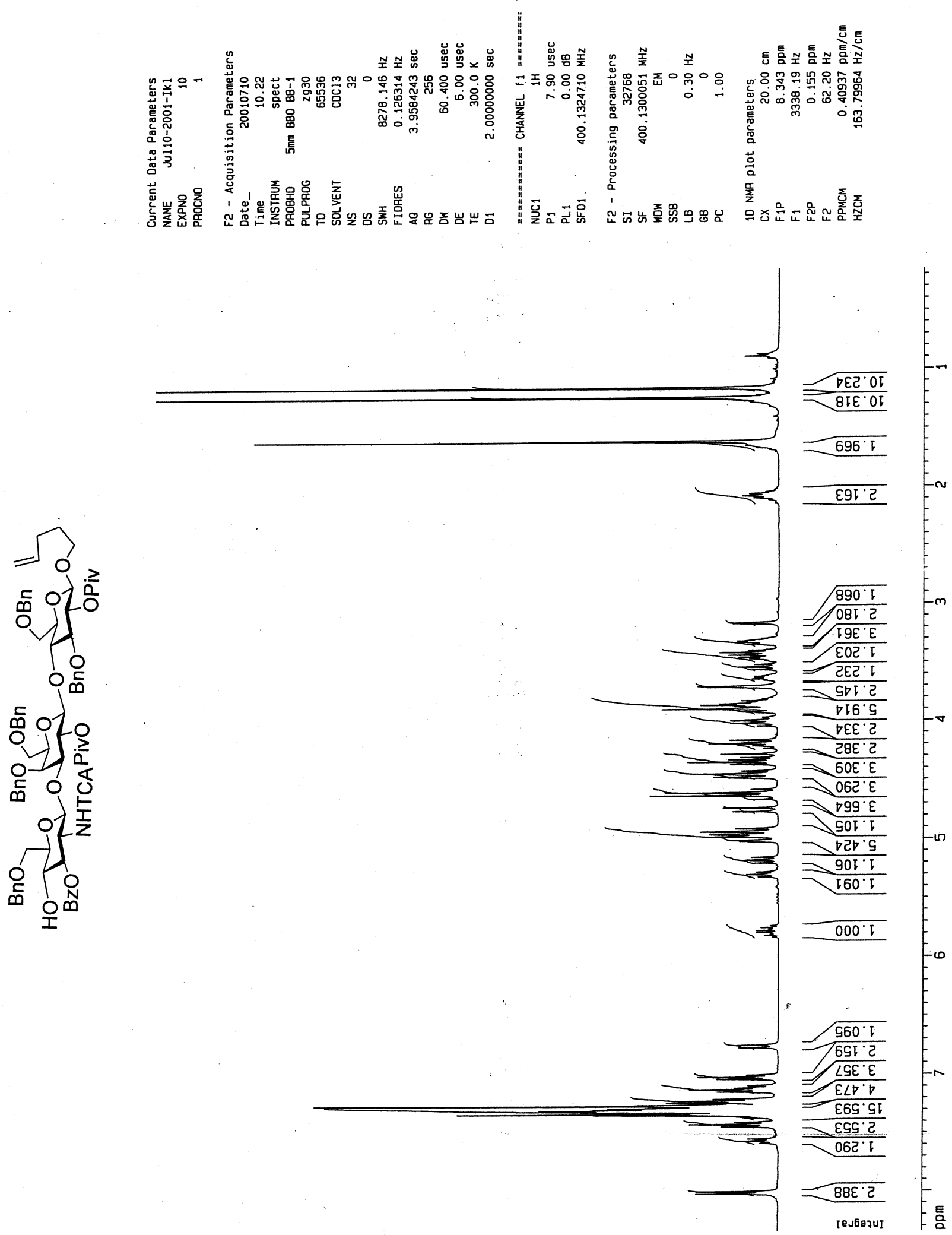


\section{Compound 11}
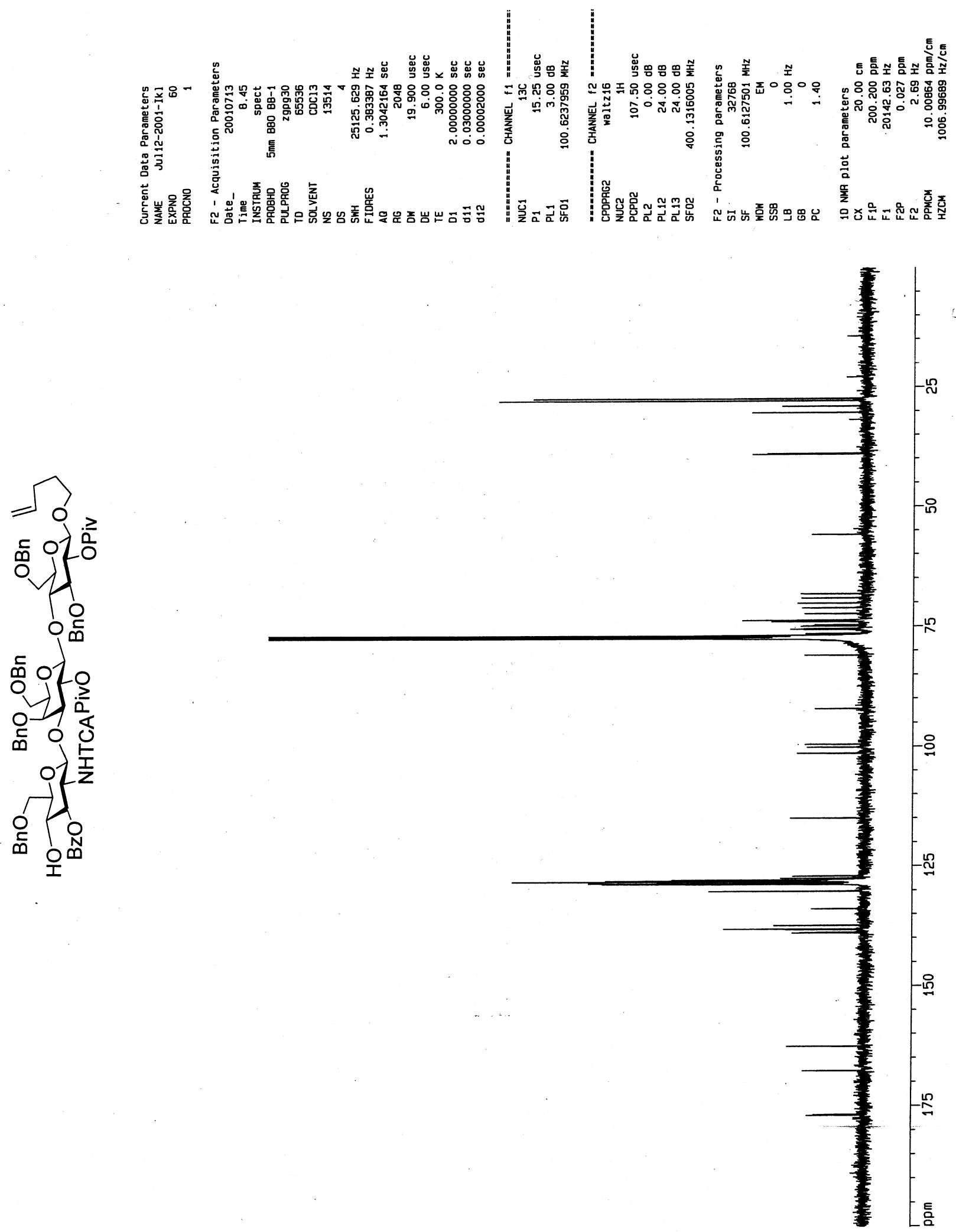
Compound 14

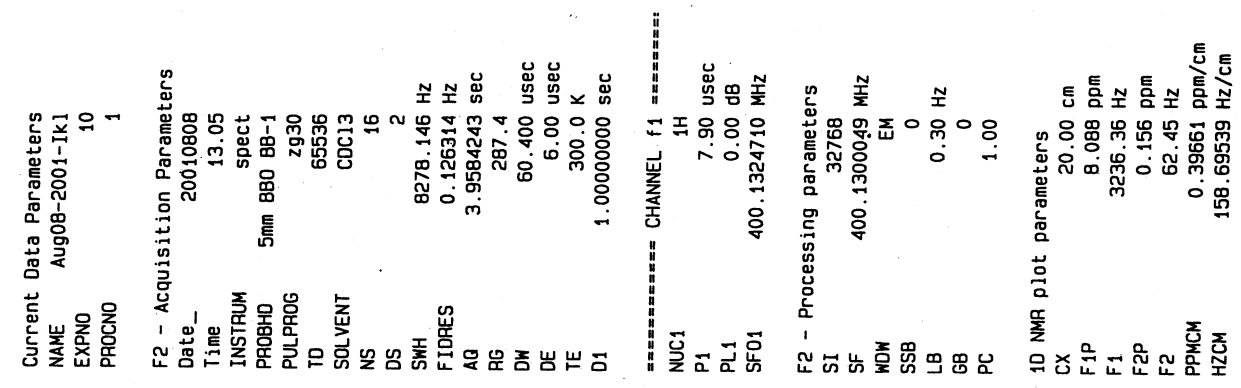

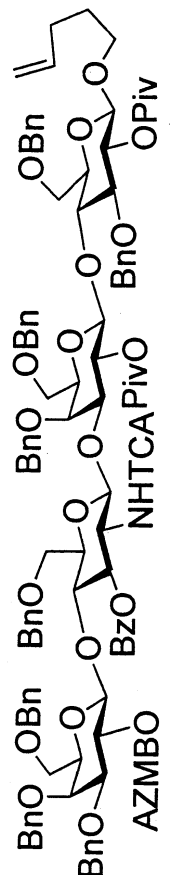

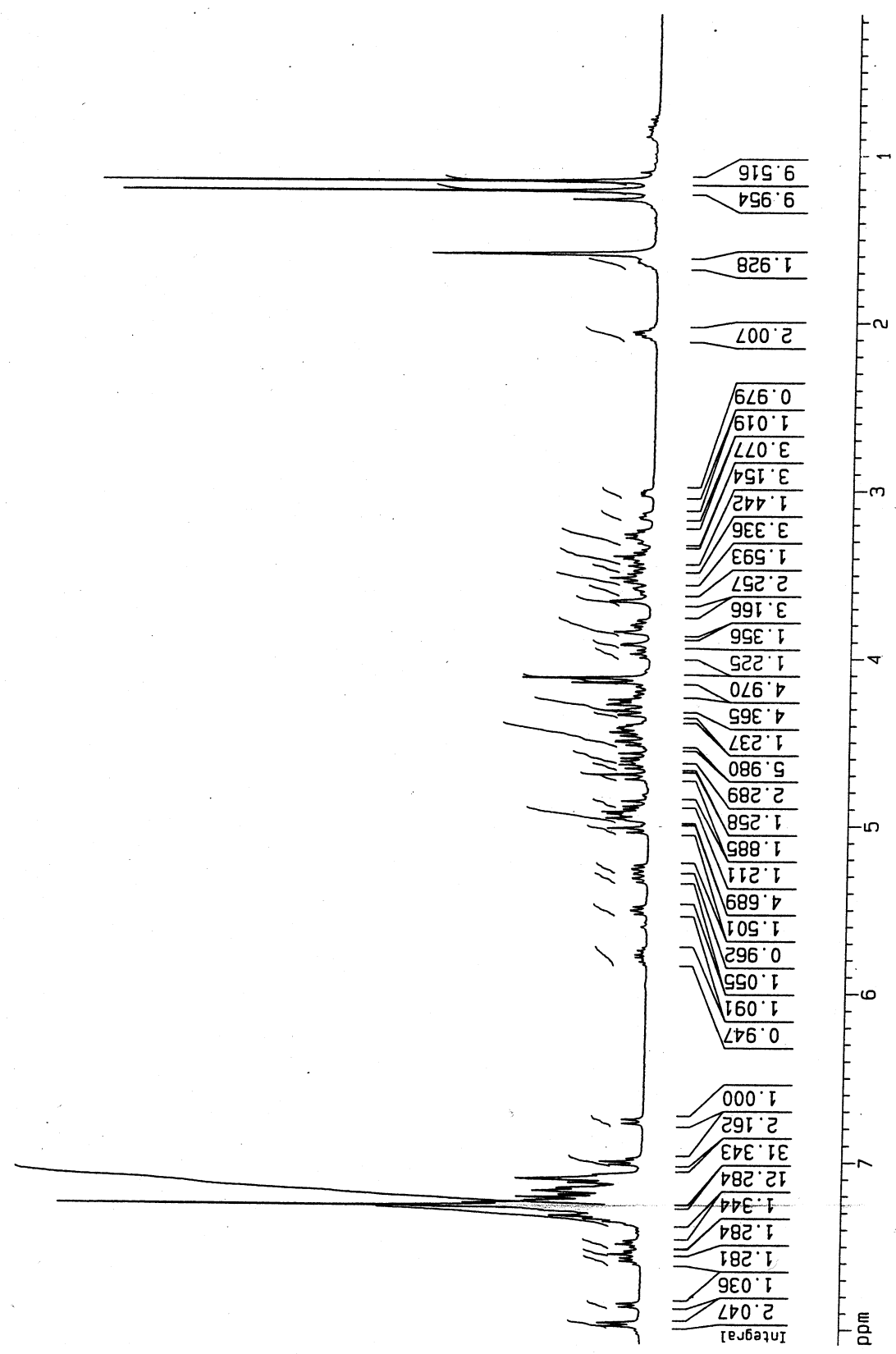


Compound 14

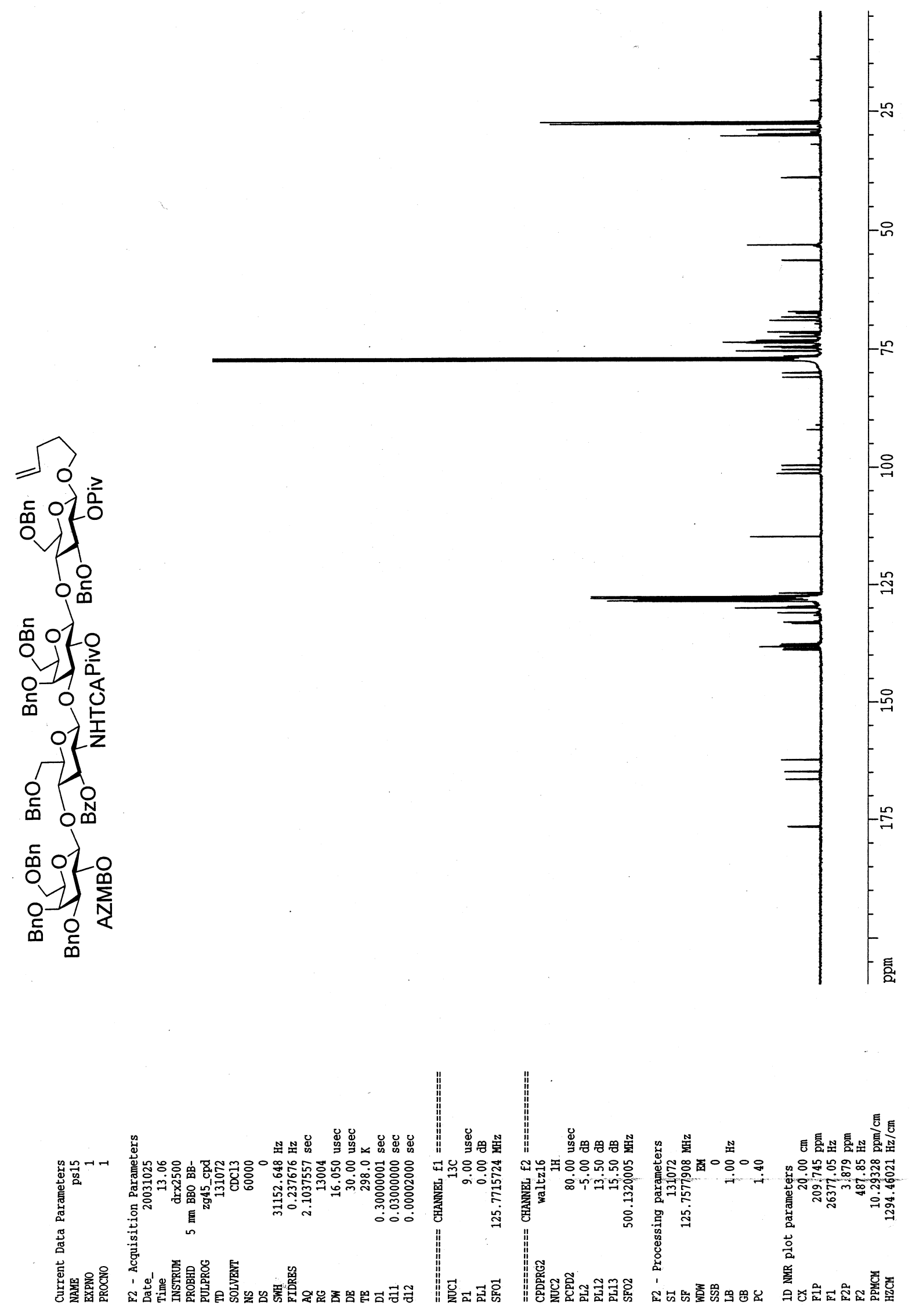


Compound 16

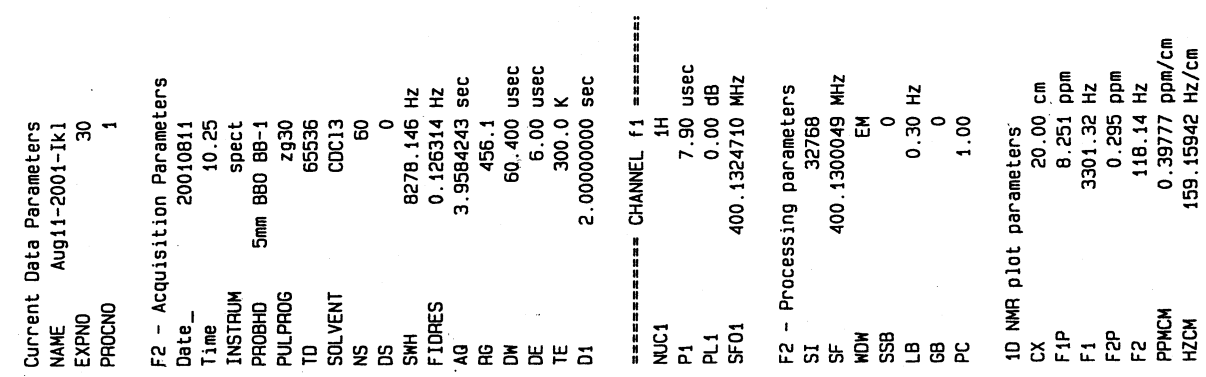

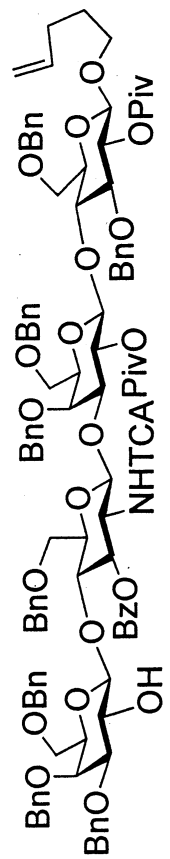

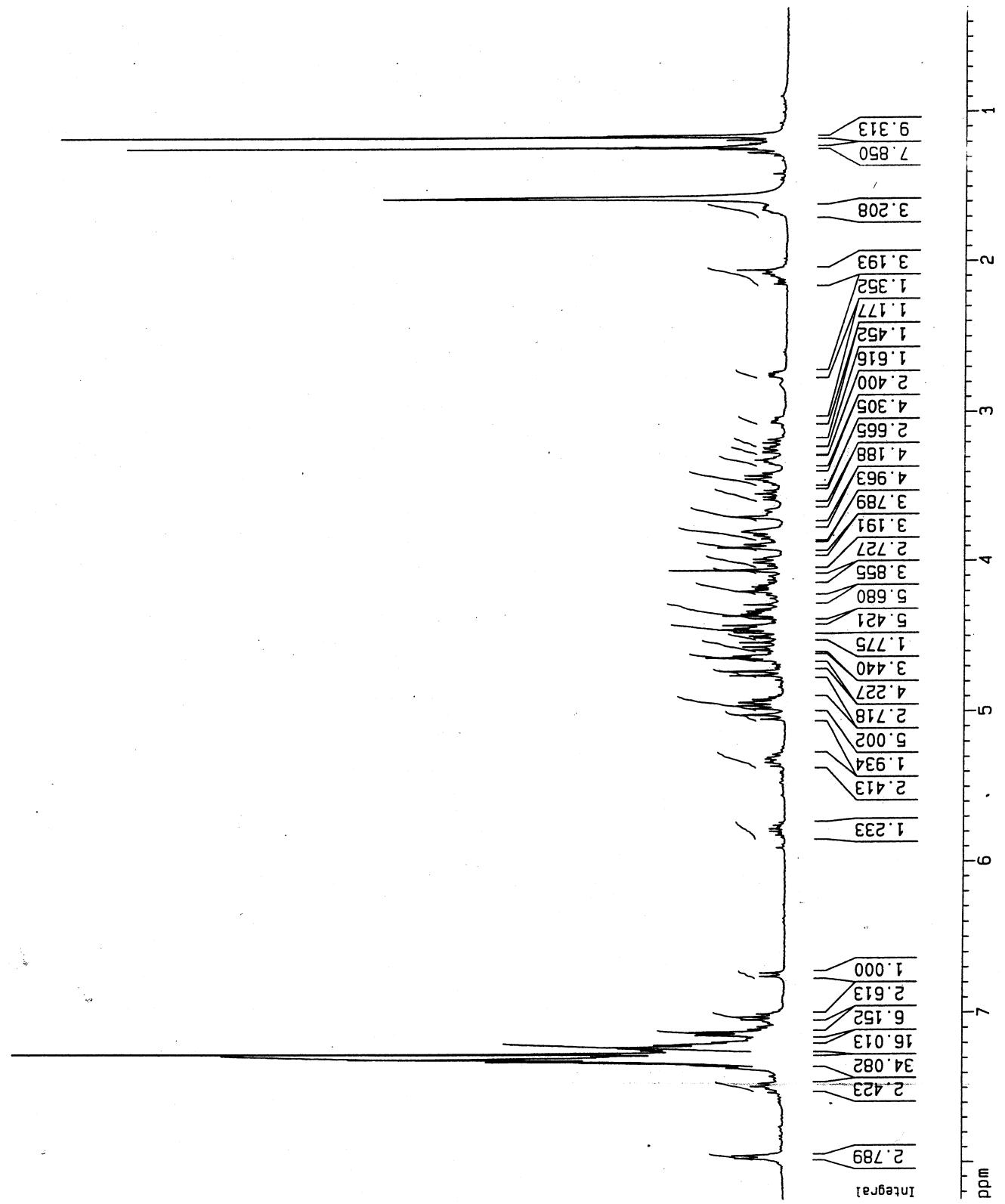


Compound 16

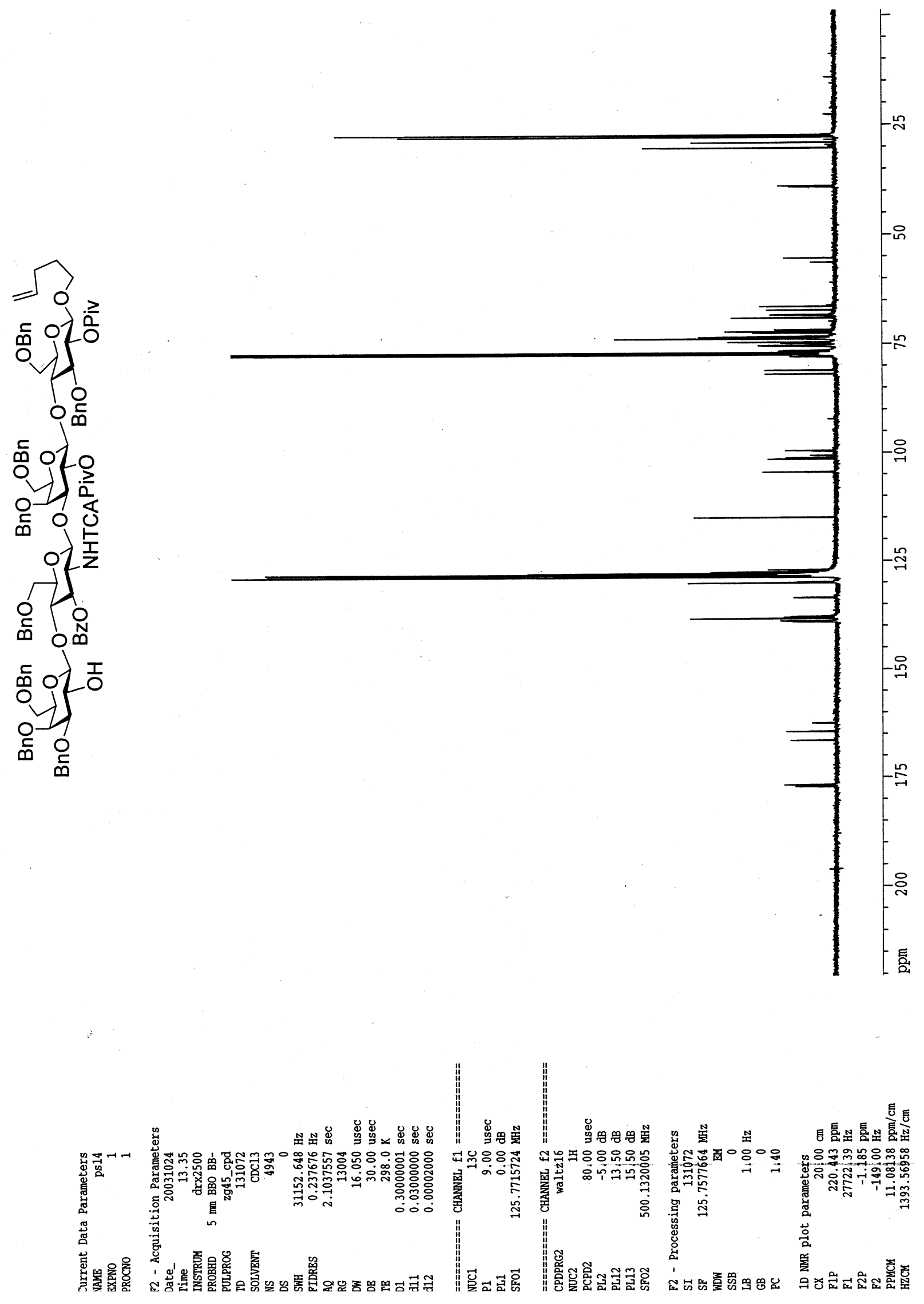


Compound 19
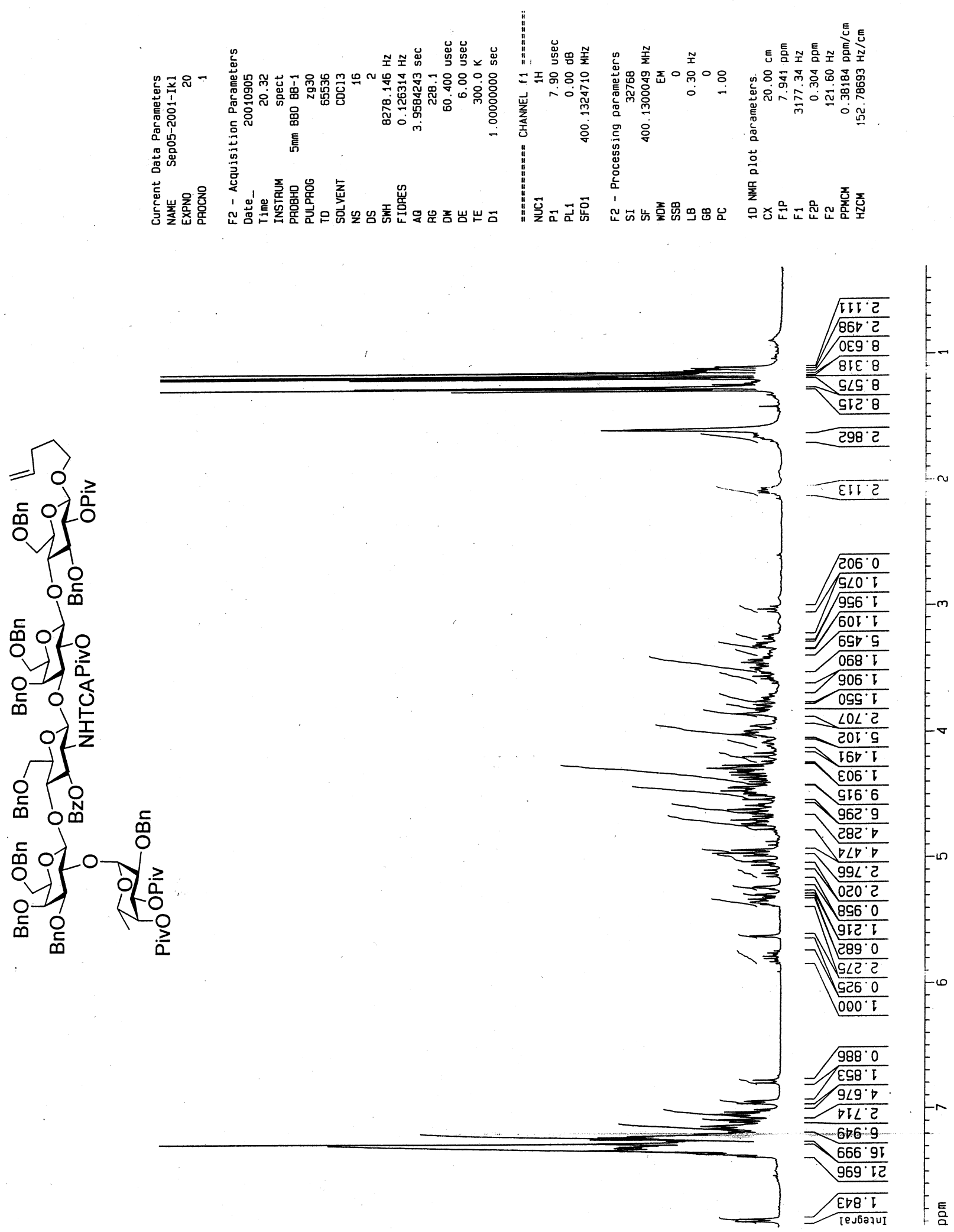
Compound 19

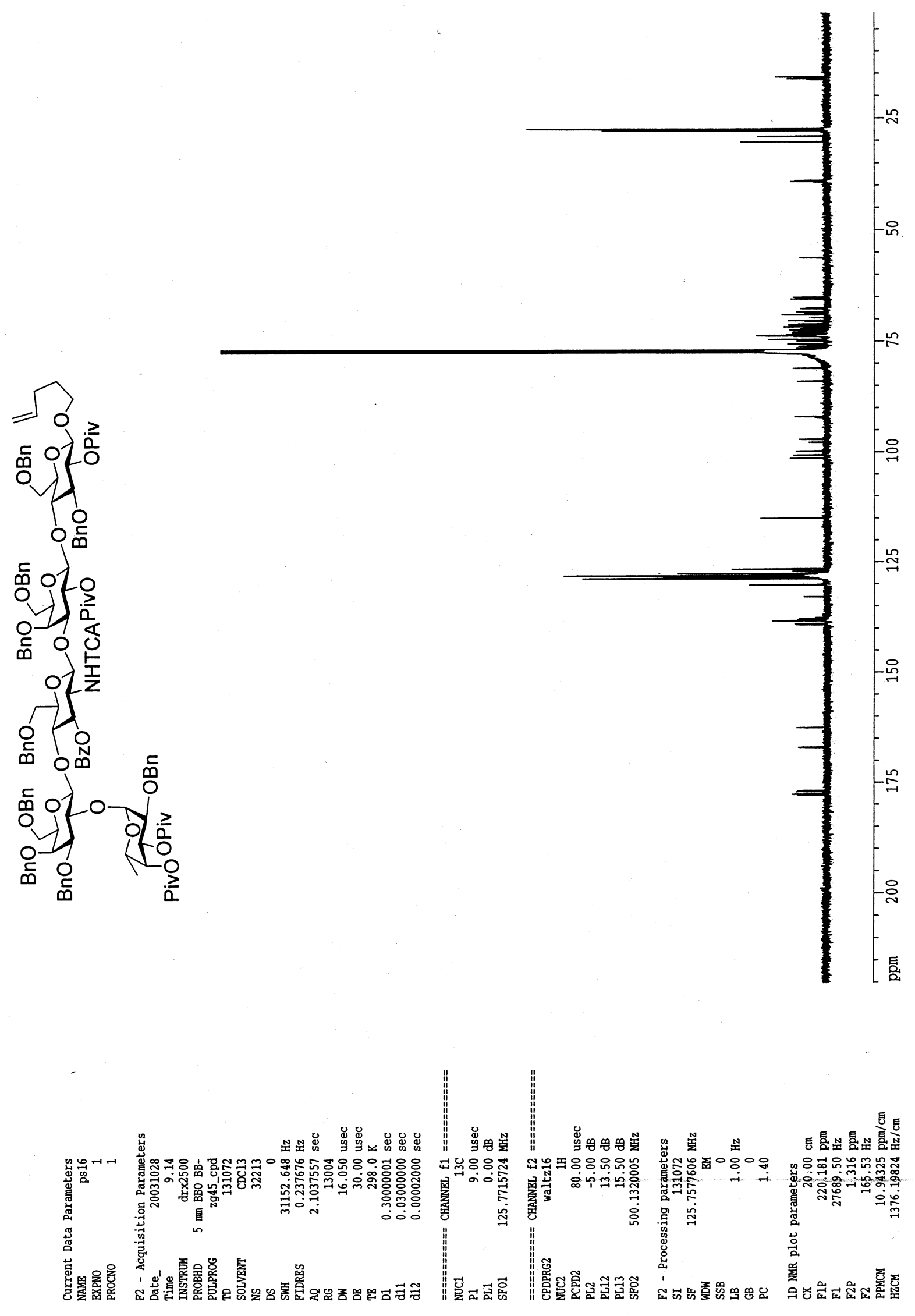




\section{Compound 36}
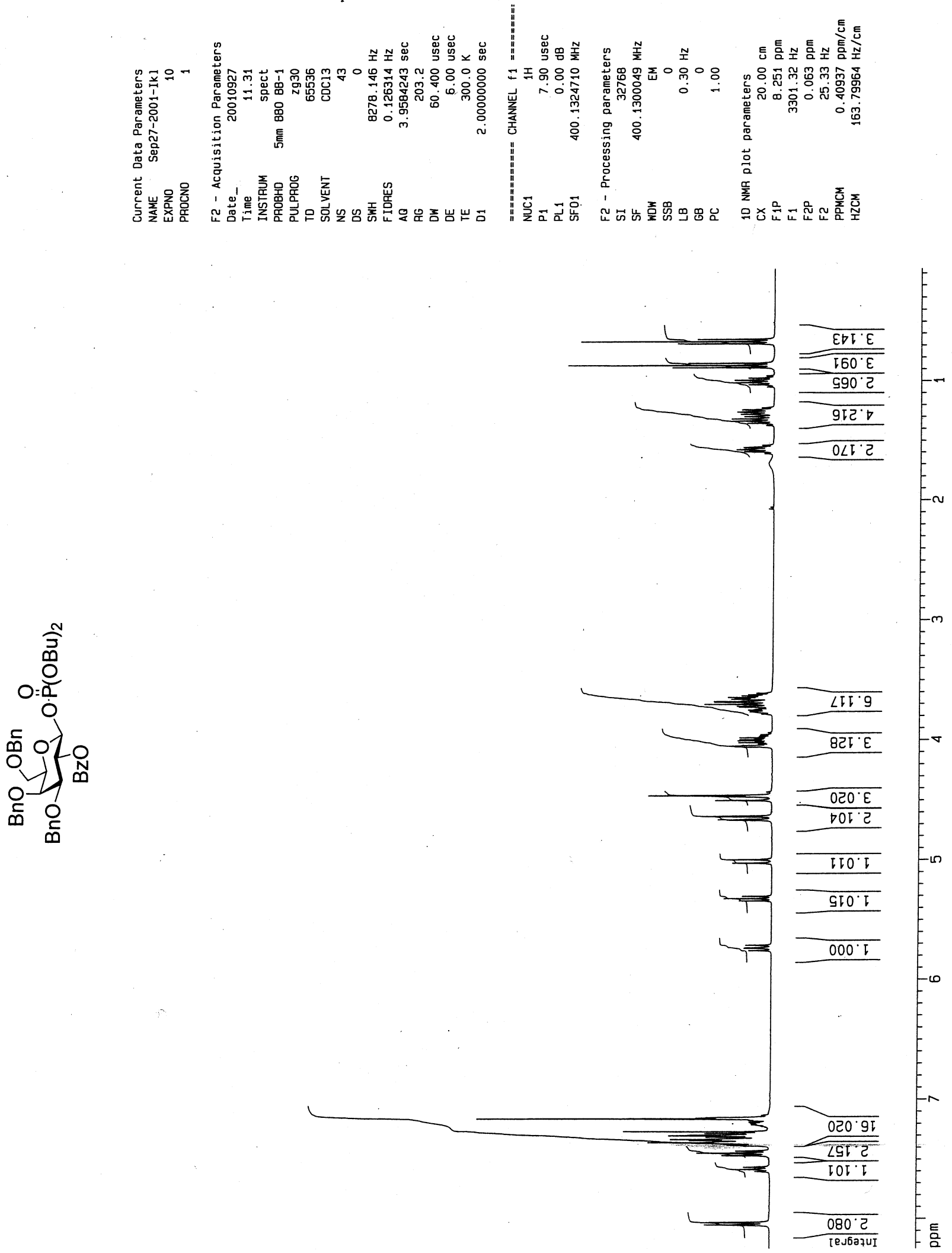
Compound 36

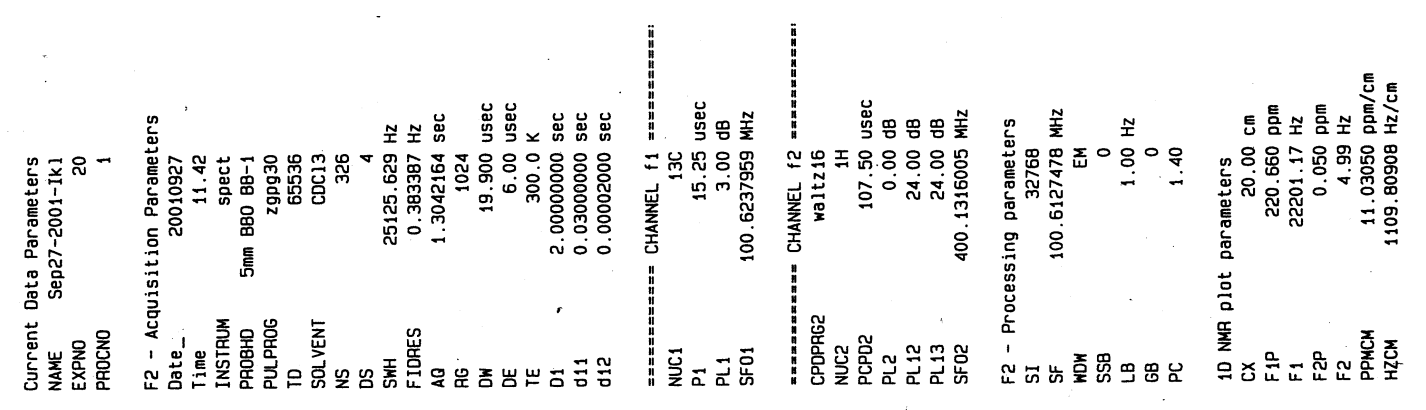

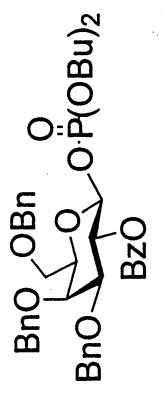

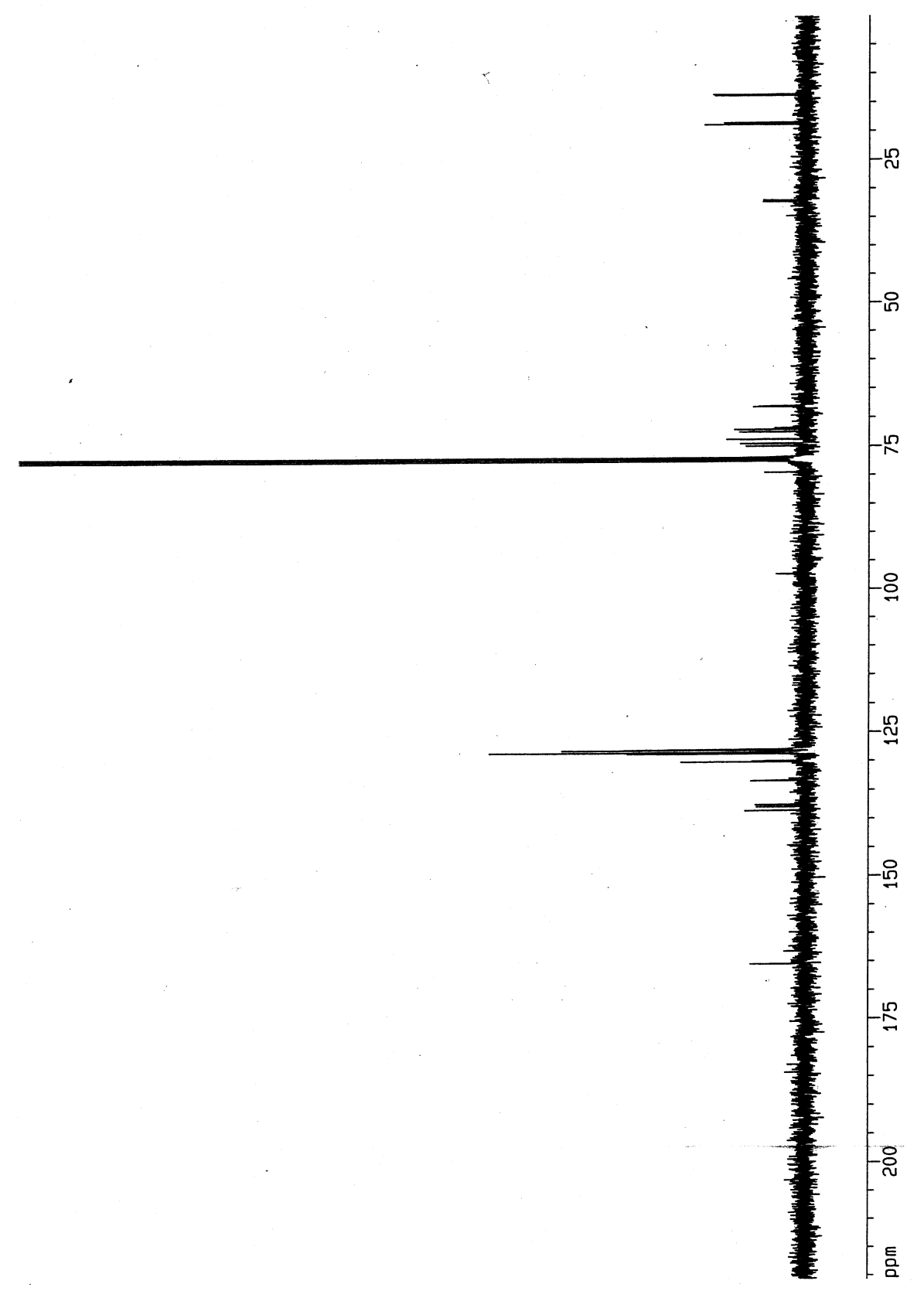


Compound 36

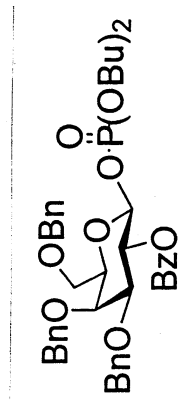

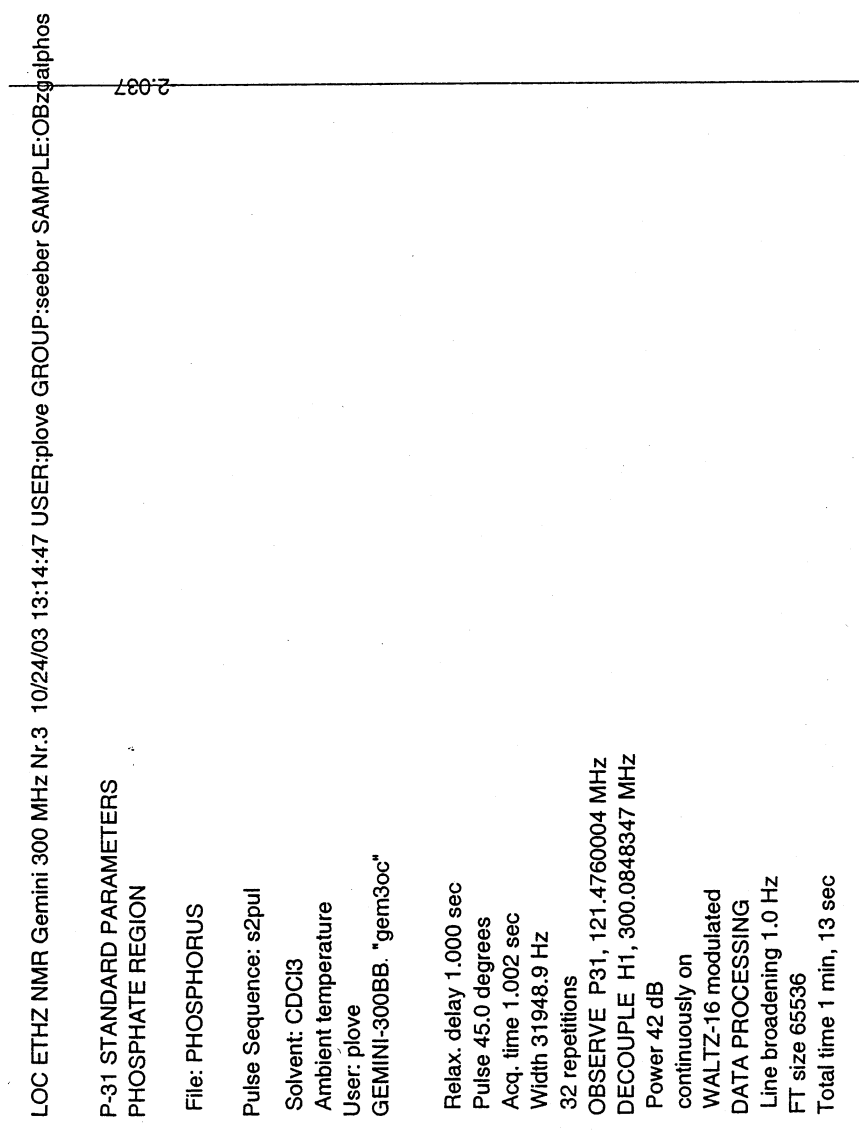




\section{Compound 32}
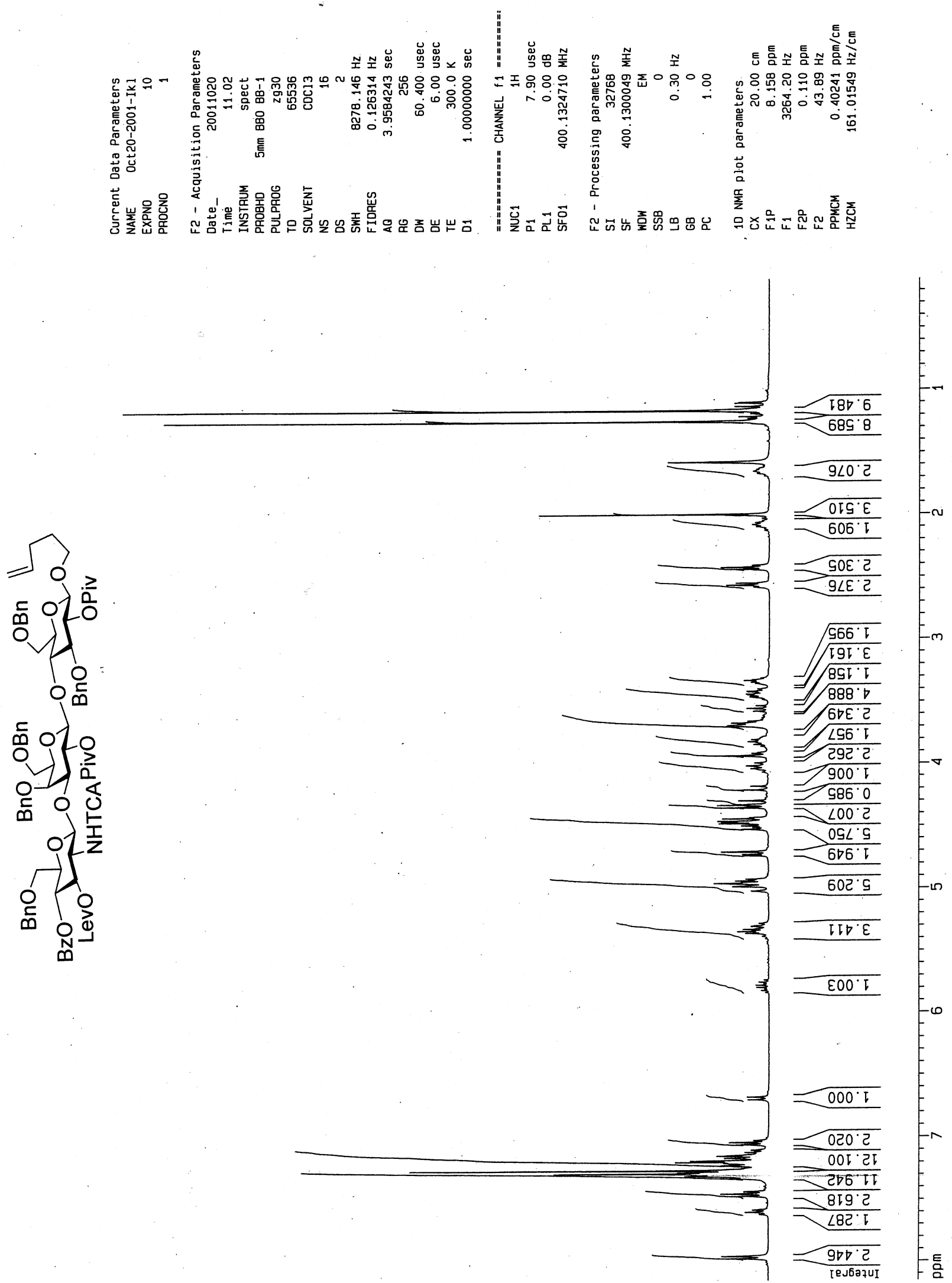


\section{Compound 32}
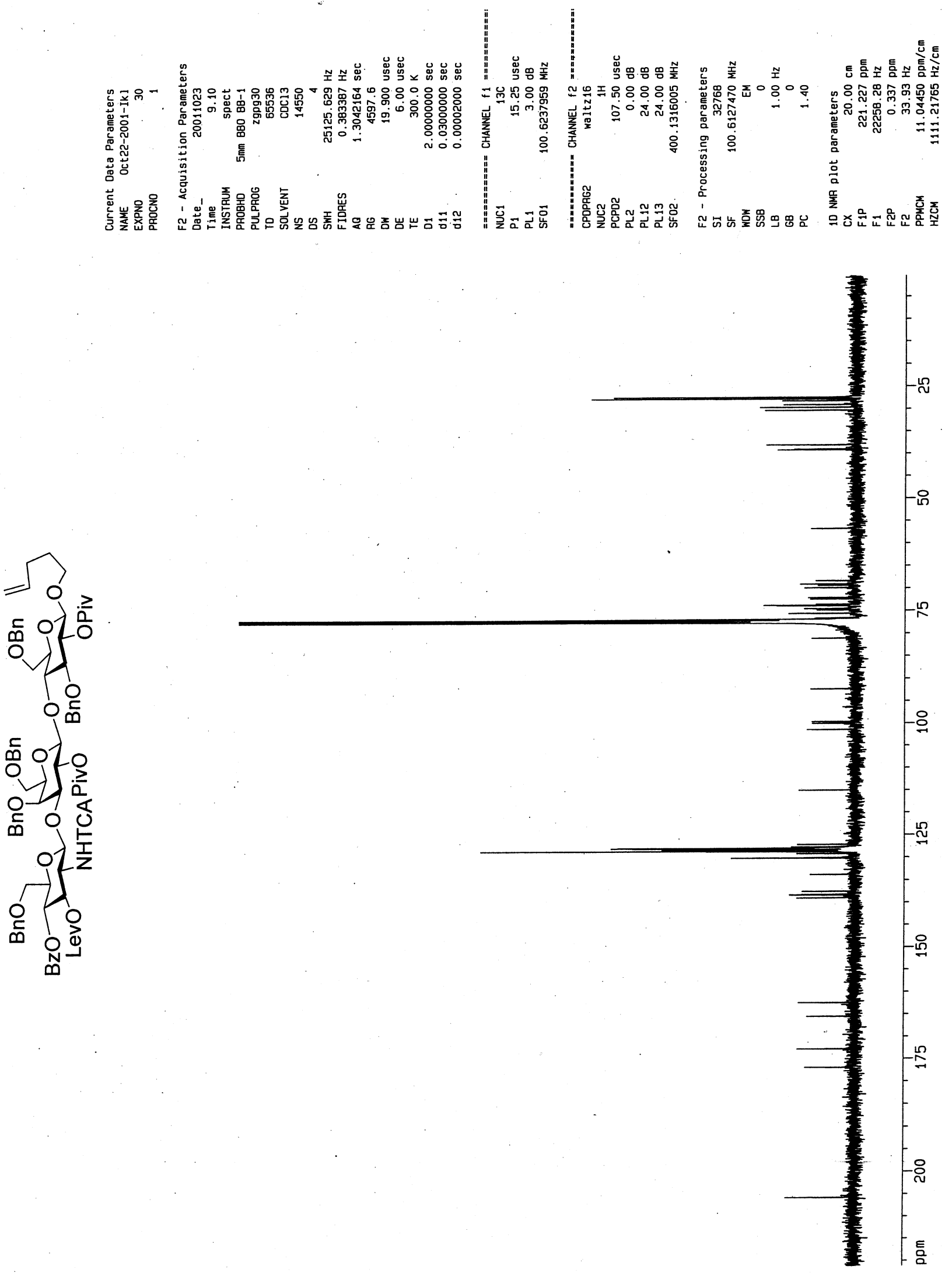
Compound 33
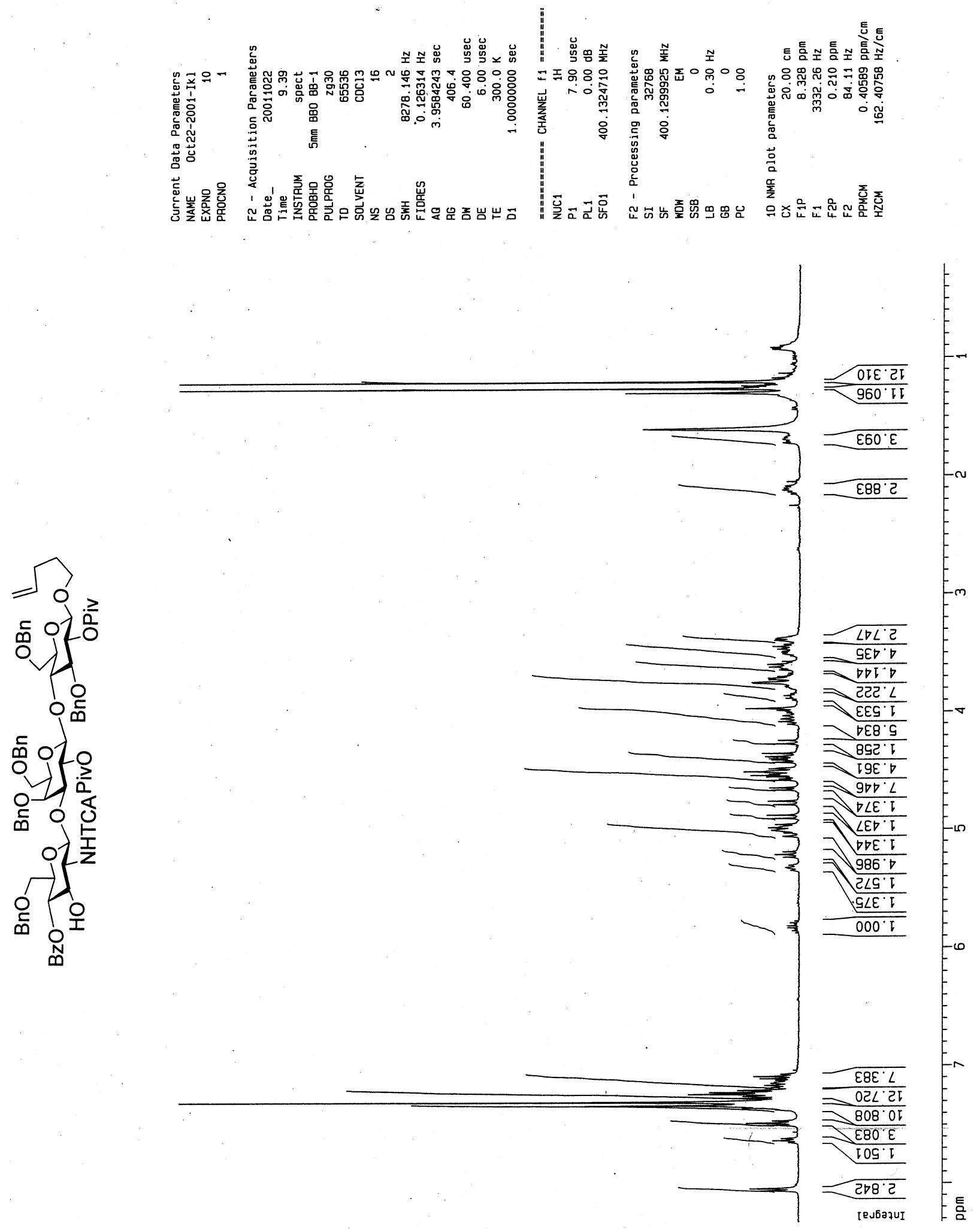
Compound 33
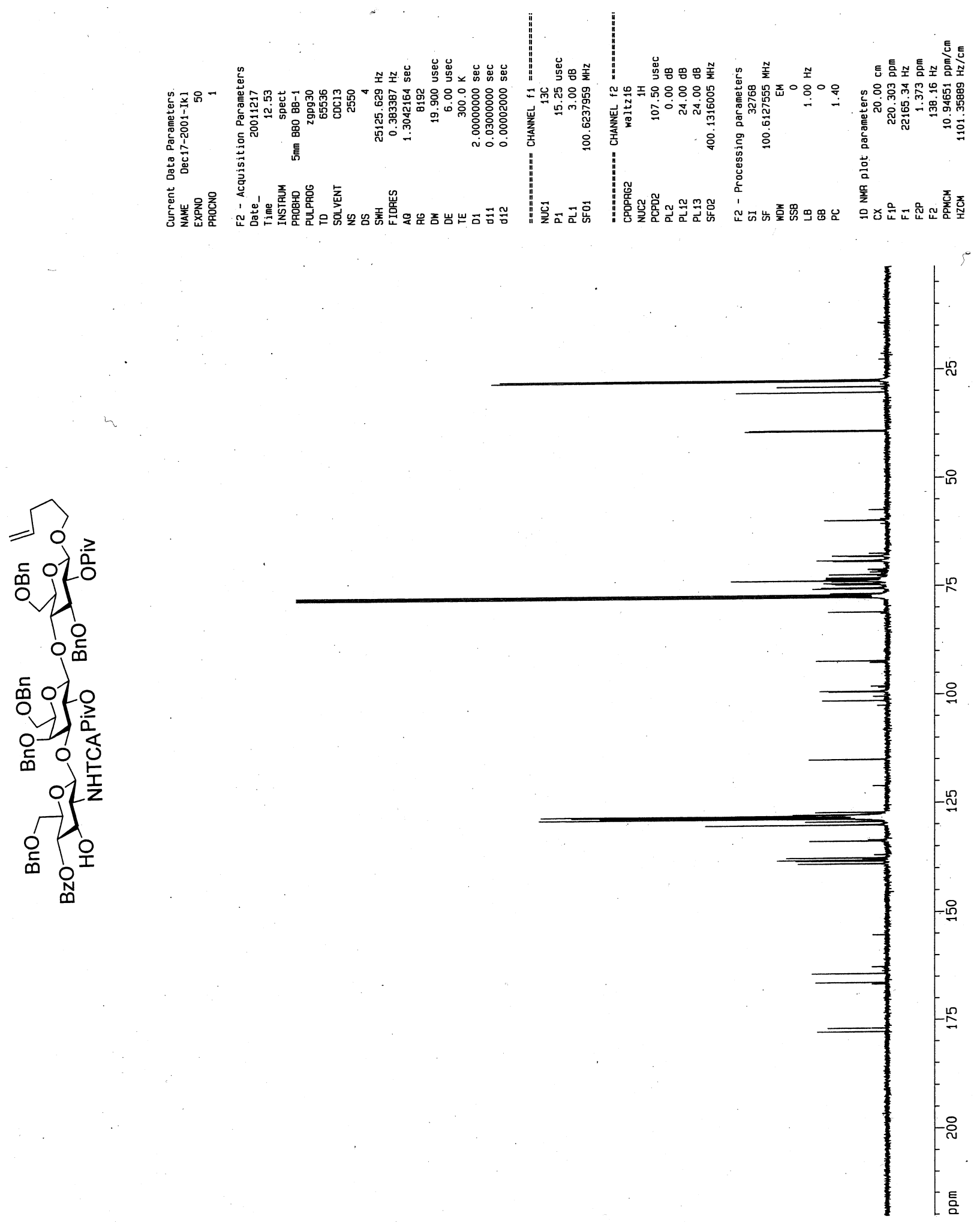


\section{Compound 34}
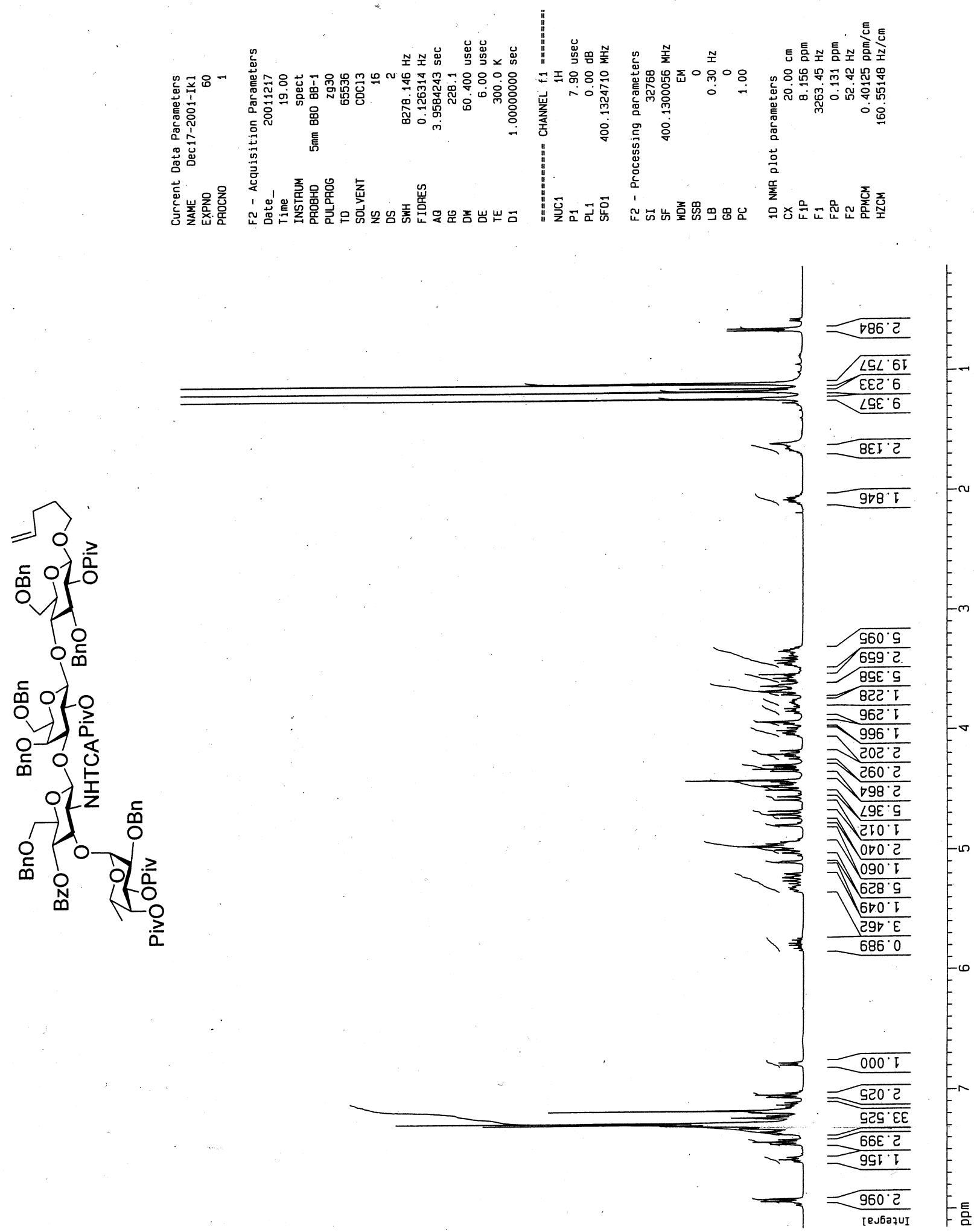
Compound 34
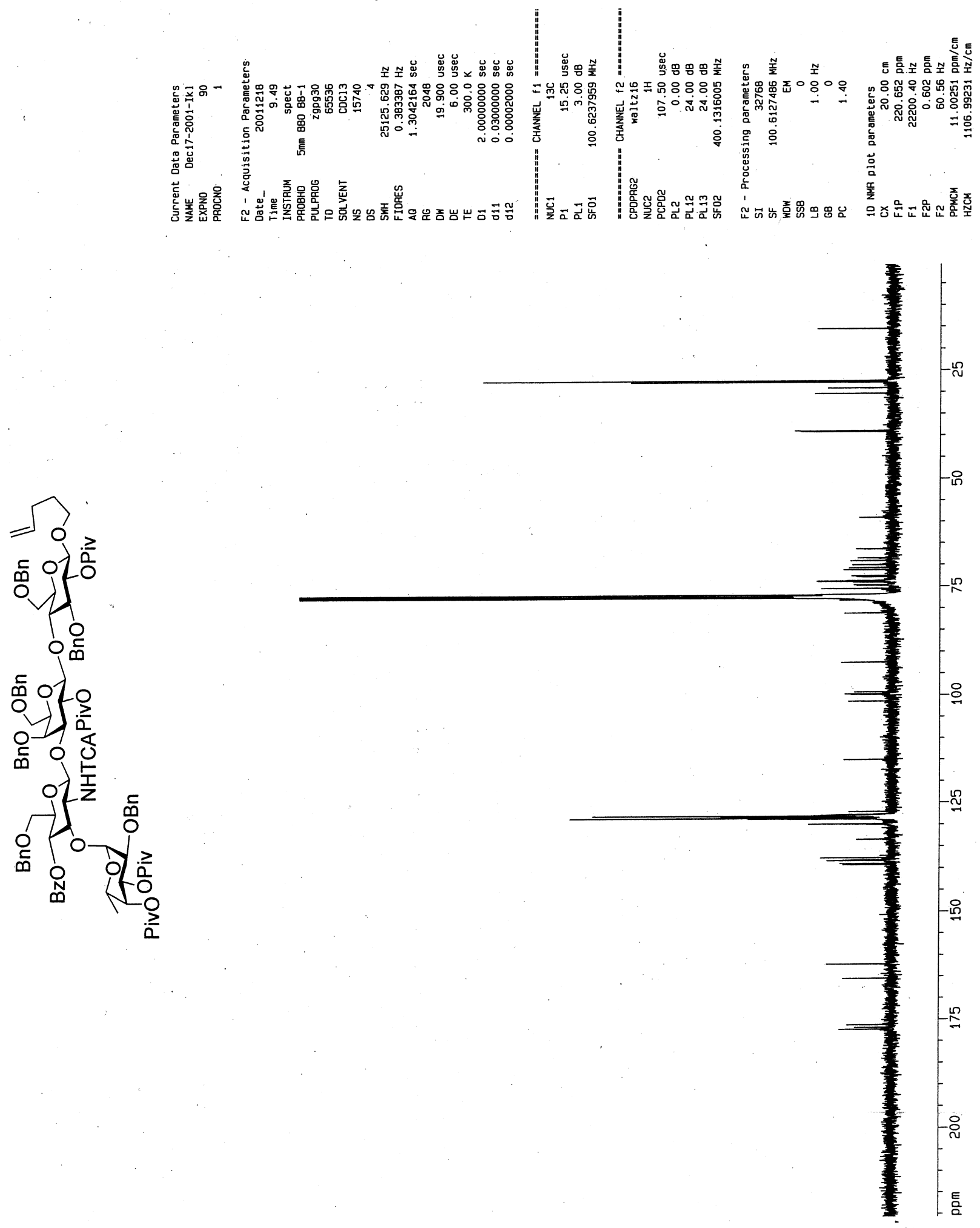


\section{Compound 35}
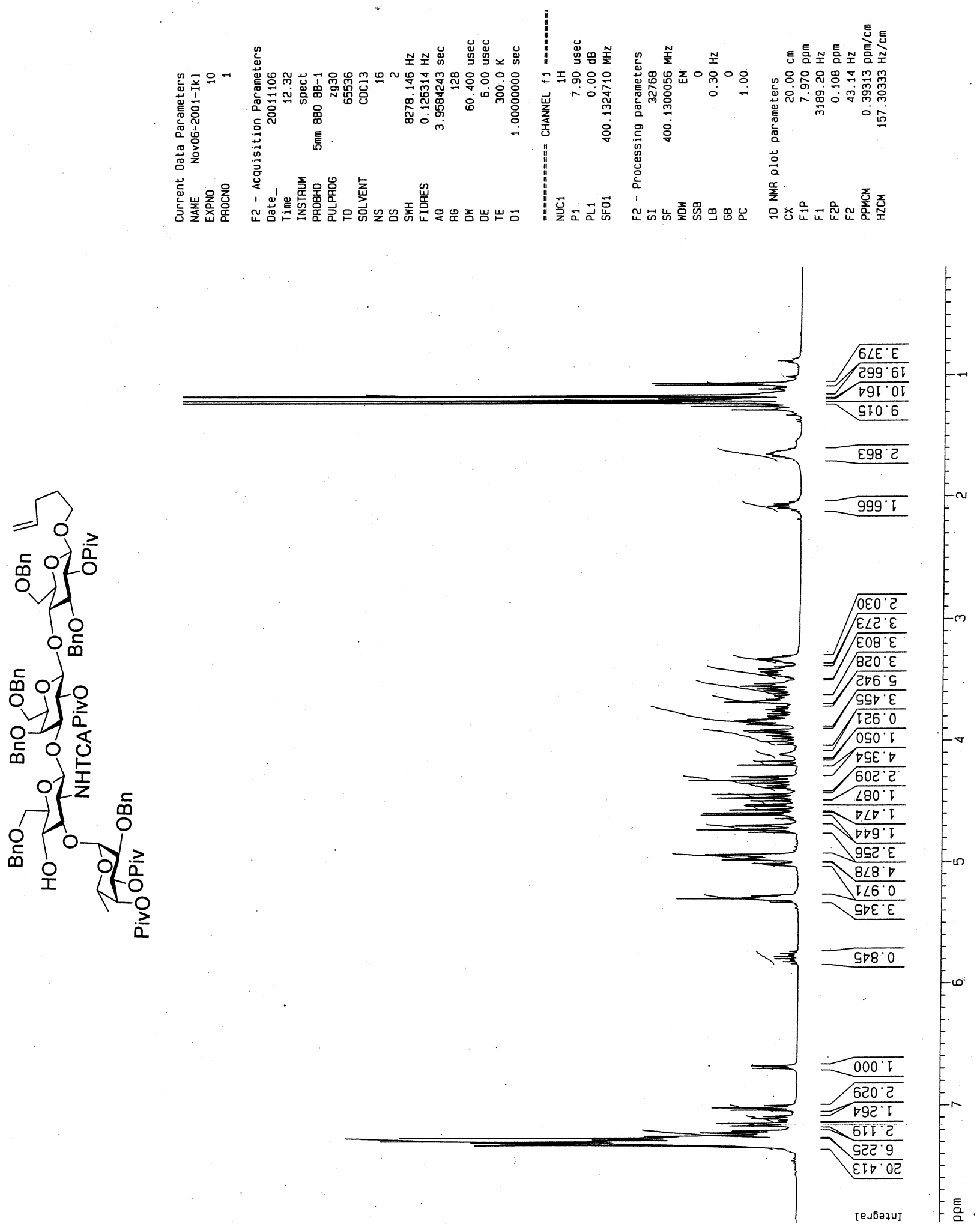
Compound 35
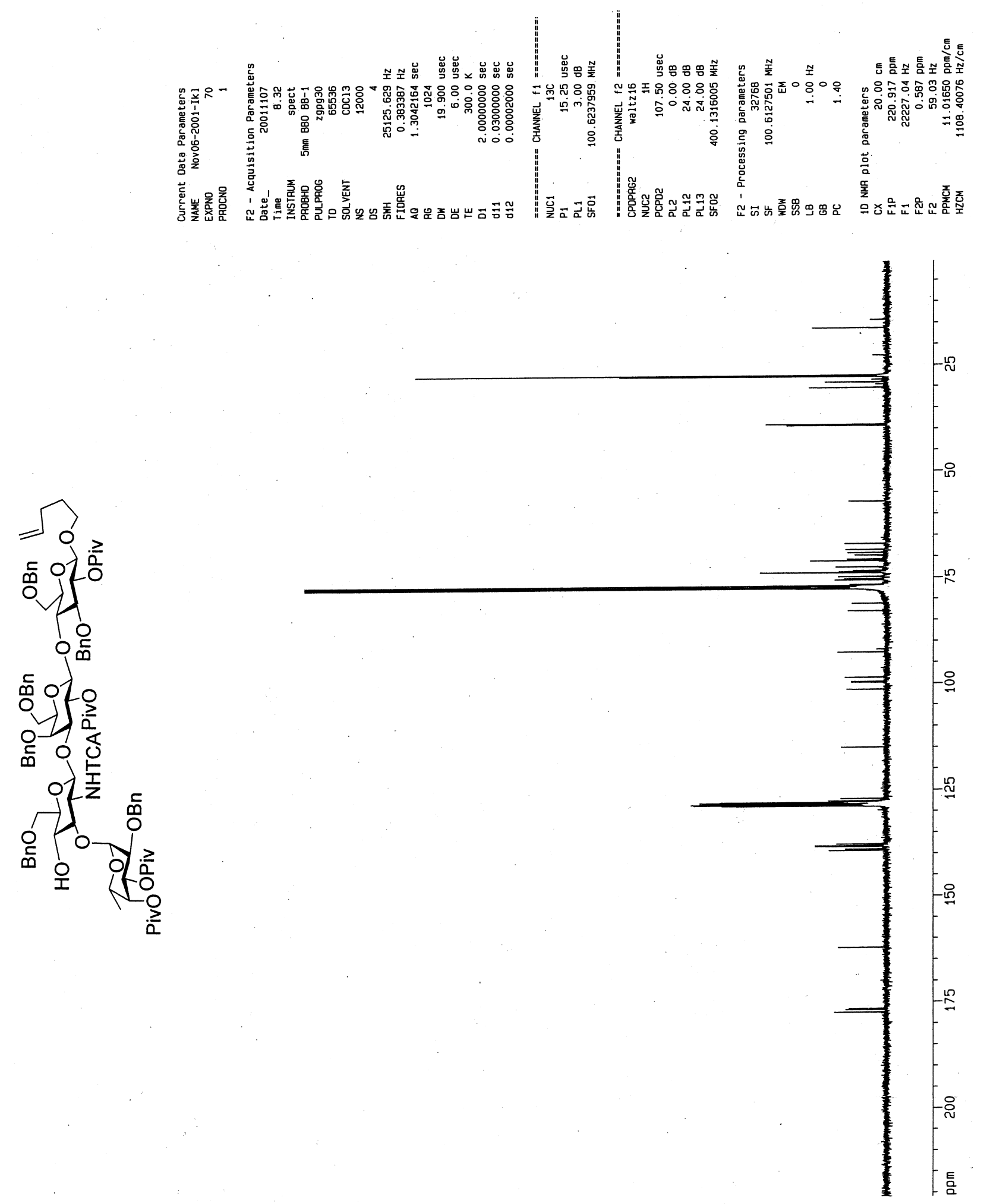
Compound 37
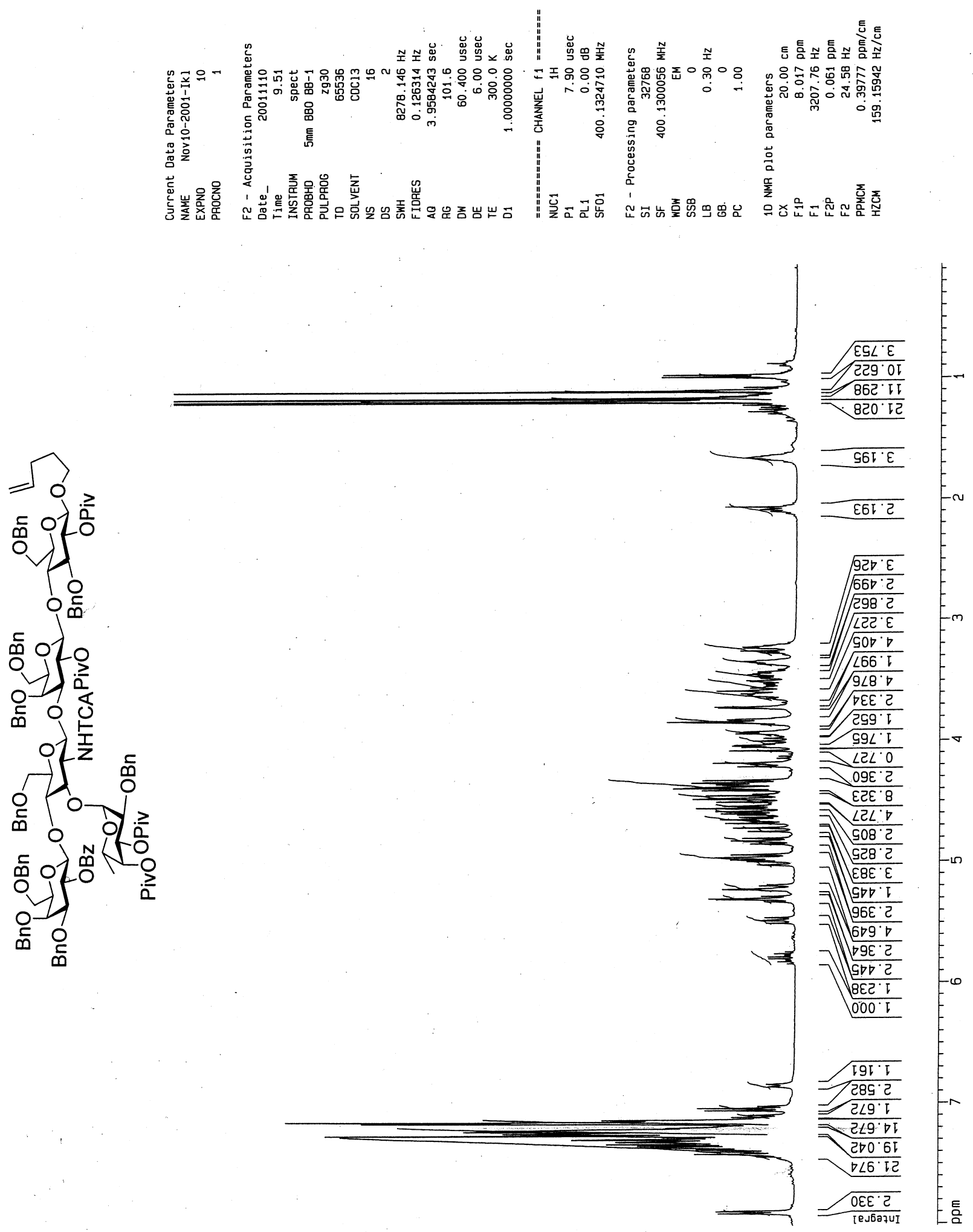
Compound 37
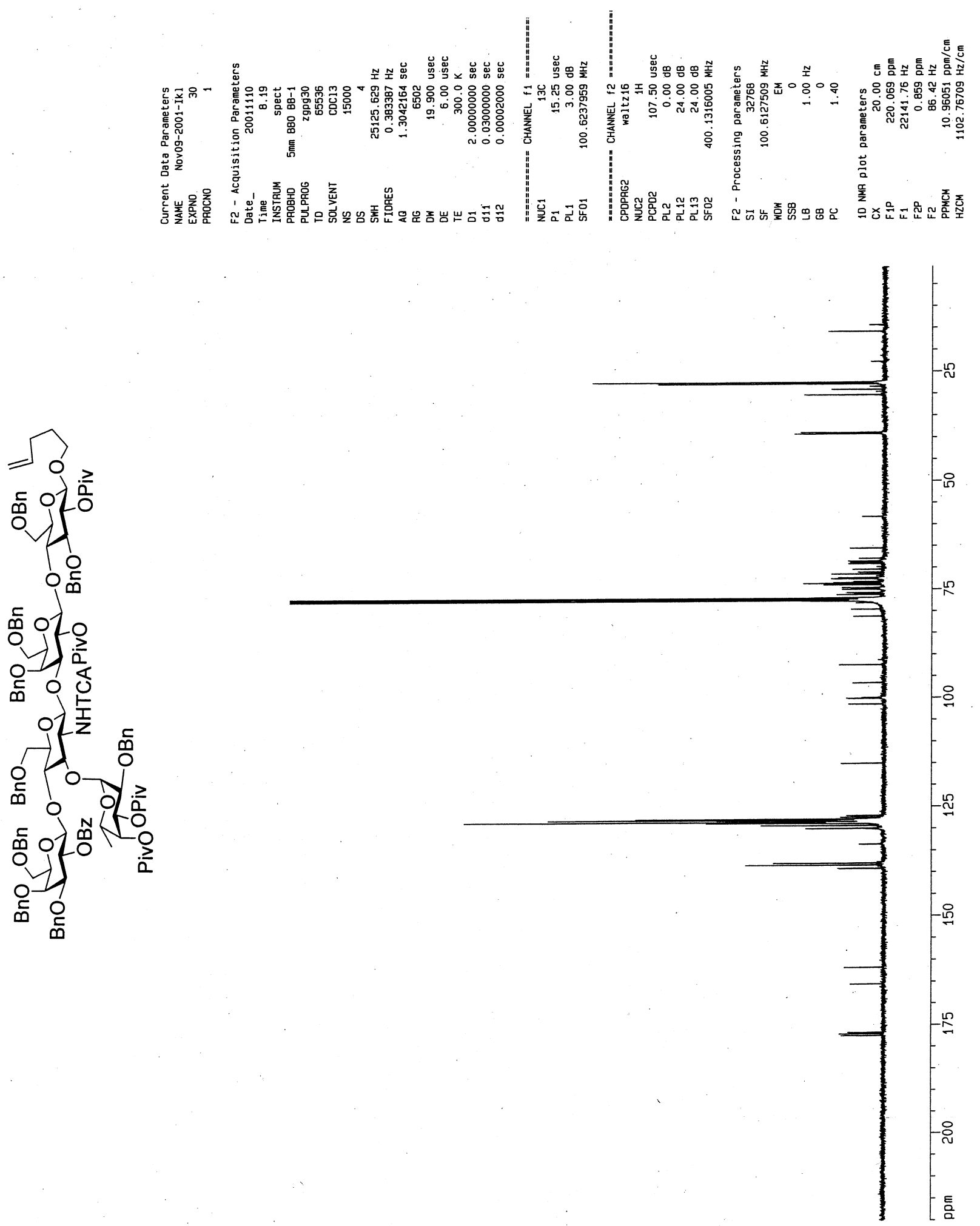
Compound 39

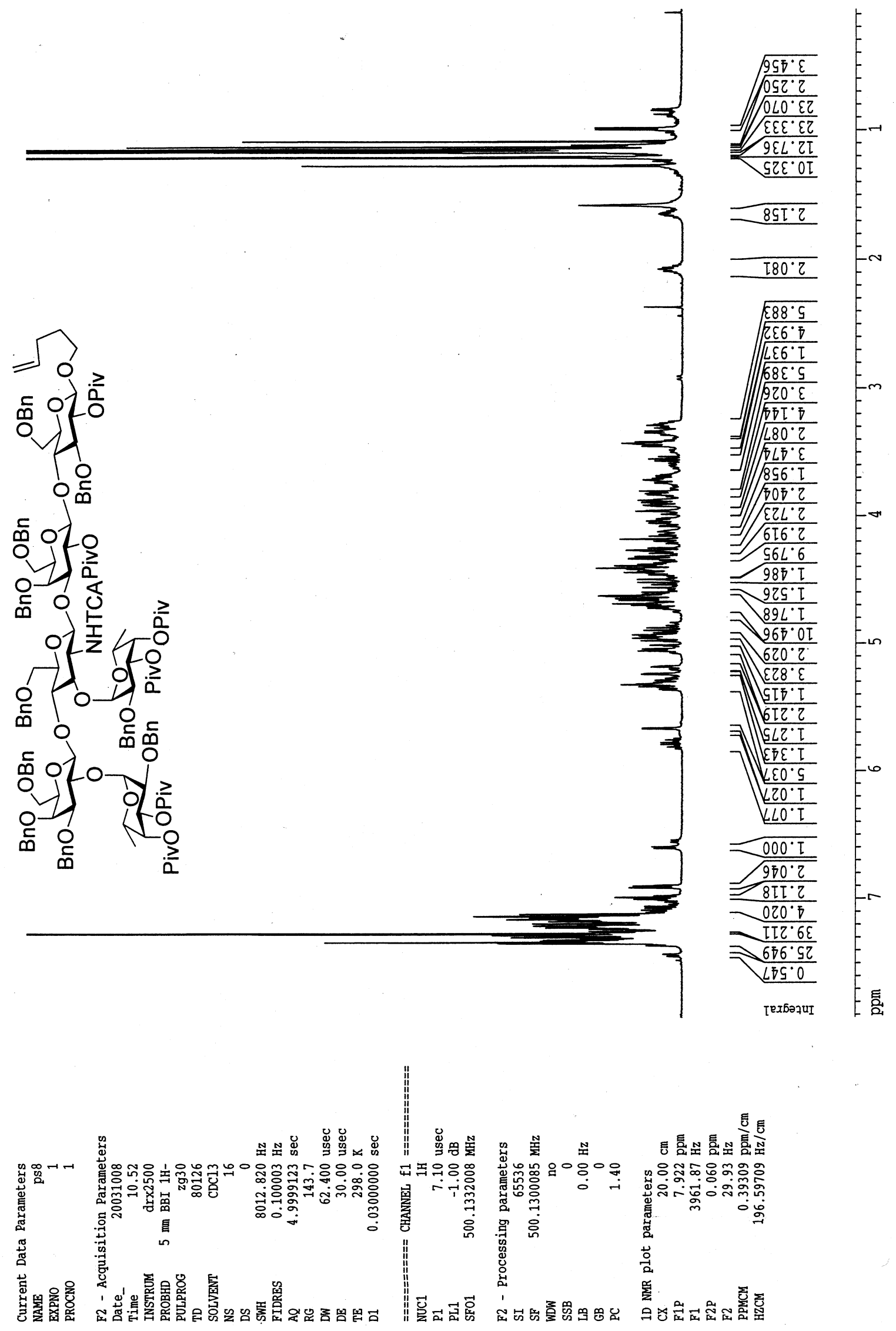




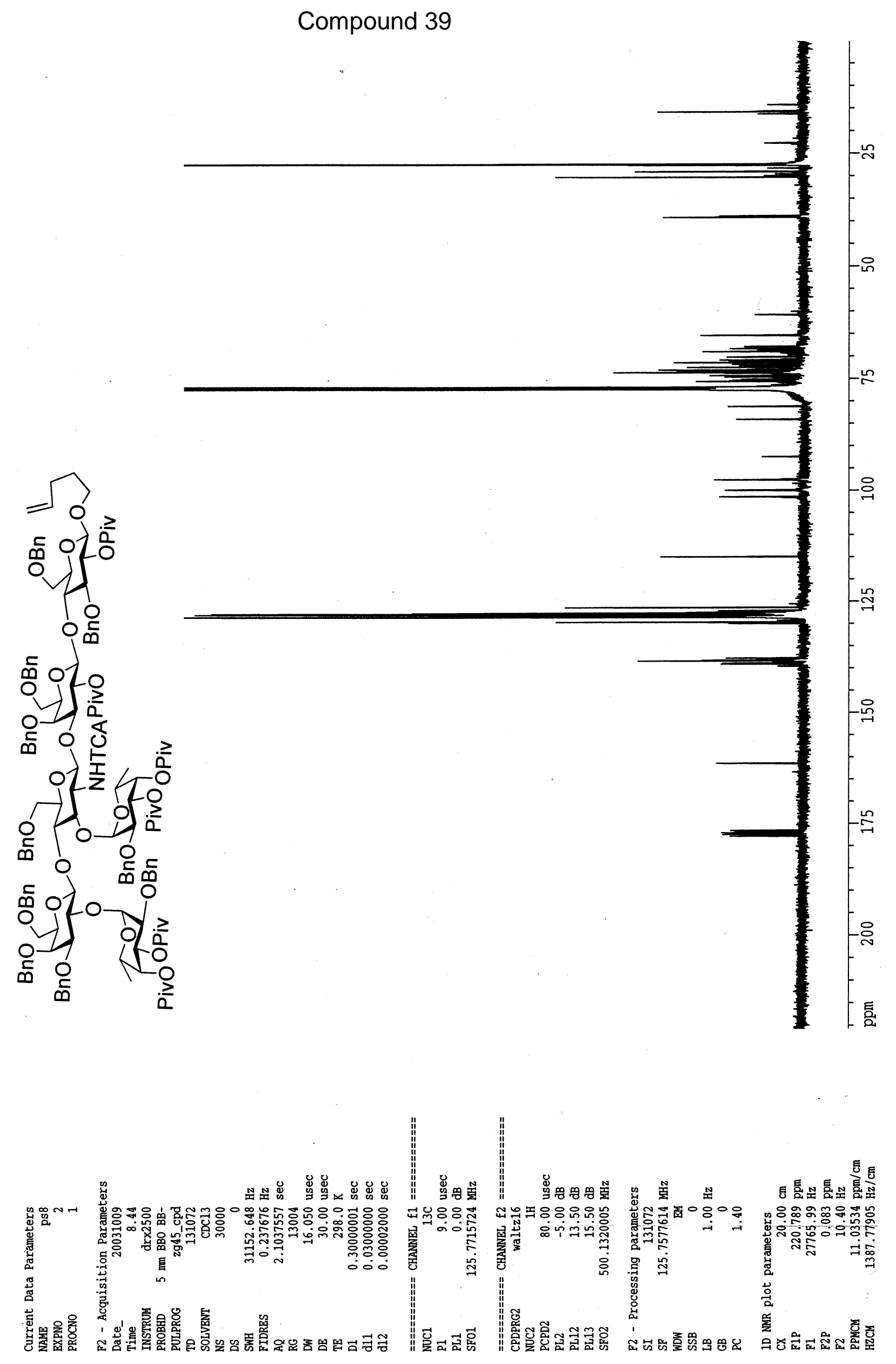

